OPEN ACCESS

Edited by:

Kelong Ai,

Central South University, China

Reviewed by:

Hongliang Liu,

Technical Institute of Physics and

Chemistry, China

Lei Jia,

Henan Polytechnic University, China

Yun Shi,

Lanzhou University, China

*Correspondence:

Zhengrong Xiong

zrxiong@ciac.ac.cn

Specialty section:

This article was submitted to

Medicinal and Pharmaceutical

Chemistry,

a section of the journal

Frontiers in Chemistry

Received: 03 January 2021

Accepted: 25 January 2021

Published: 23 April 2021

Citation:

Gao F and Xiong Z (2021) Reactive Oxygen Species Responsive Polymers

for Drug Delivery Systems.

Front. Chem. 9:649048.

doi: 10.3389/fchem.2021.649048

\section{Reactive Oxygen Species Responsive Polymers for Drug Delivery Systems}

\author{
Fengxiang Gao ${ }^{1,2}$ and Zhengrong Xiong ${ }^{1,3 *}$ \\ ${ }^{1}$ University of Science and Technology of China, Hefei, China, ${ }^{2}$ Key Laboratory of Polymer Ecomaterials, Changchun Institute of \\ Applied Chemistry CAS, Chinese Academy of Sciences, Changchun, China, ${ }^{3}$ Polymer Composites Engineering Laboratory, \\ Changchun Institute of Applied Chemistry CAS, Chinese Academy of Sciences, Changchun, China
}

Reactive oxygen species (ROS) play an essential role in regulating various physiological functions of living organisms; however, as the concentration of ROS increases in the area of a lesion, this may undermine cellular homeostasis, leading to a series of diseases. Using cell-product species as triggers for targeted regulation of polymer structures and activity represents a promising approach for the treatment. ROS-responsive polymer carriers allow the targeted delivery of drugs, reduce toxicity and side effects on normal cells, and control the release of drugs, which are all advantages compared with traditional smallmolecule chemotherapy agents. These formulations have attracted great interest due to their potential applications in biomedicine. In this review, recent progresses on ROS responsive polymer carriers are summarized, with a focus on the chemical mechanism of ROS-responsive polymers and the design of molecular structures for targeted drug delivery and controlled drug release. Meanwhile, we discuss the challenges and future prospects of its applications.

Keywords: ROS, responsive polymers, nanomaterial, drug carriers, targeted delivery

Most common cytotoxic drugs present shortcomings such as short circulation in vivo, poor targeting, low drug availability rates, and frequent side effects, which greatly reduce their efficacy and severely limit their clinical application. Thus, it is essential to encapsulate drug and design controlled release preparations. Fortunately, there are numerous differences in the pathological microenvironment compared to normal tissue, such as enzyme levels, $\mathrm{pH}$, temperature, and ionic strength; among these factors, the most remarkable are the differences in reactive oxygen species (ROS) levels (De Palma et al., 2017). A significant increase in metabolite levels or inflammatory signals could lead to an increase in ROS levels (D'Autreaux and Toledano, 2007). For example, the concentration of $\mathrm{H}_{2} \mathrm{O}_{2}$ in normal tissues is strictly controlled at about $20 \mathrm{nmol} \mathrm{L}^{-1}$, while the concentration of $\mathrm{H}_{2} \mathrm{O}_{2}$ in tumor tissues increases up to $50-100 \mathrm{~mol} \mathrm{~L}^{-1}$. ROS levels in tumor cells are significantly higher than those in normal cells (Schumacker, 2015). In addition, increased ROS levels are associated with cardiovascular and cerebrovascular diseases (atherosclerosis and hypertension), diabetes, and neurodegenerative diseases (Alzheimer's disease). Thus, ROS are ideal markers for active targeting and inducing the controlled release of drugs (Yang et al., 2019). The development of a ROS-responsive drug delivery system is very important and has excellent prospects for application in the biomedicine field (Trachootham et al., 2009; Song et al., 2014).

Nanodrugs based on currently available polymer carriers present the numerous advantages compared with inorganic substances and small molecules. Polymer carriers exhibit better biocompatibility and generally do not contain heavy metal elements. It is possible to introduce specific functional groups or multiple groups on the polymer chains, and formulate multifunctional targets to achieve personalized therapy. Moreover, different nanostructures, such as vesicles, solid 
TABLE 1 | ROS-responsive polymer structures and mechanisms of activity (Ye et al., 2019). Copyright 2019, the American Chemical Society.

Hydrophobic to hydrophilic phase transition

Thioether

Selenium

Tellurium

Structural cleavage

Thioketal

Arylboronic acid/esters containing polymers<smiles>CCSC(C)(C)SCC</smiles><smiles>CCP(CC)CC</smiles>

$\mathrm{R}=\mathrm{S}, \mathrm{Se}, \mathrm{Te}$

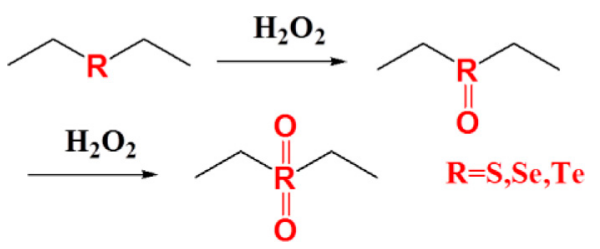

Aryl oxalate ester<smiles>CCOC(=O)C(=O)Oc1ccc(C)cc1</smiles><smiles>CCSC(C)(C)SC[Te]CCC[Si]C=O</smiles><smiles>COCc1ccc(B(OC(C)(C)C(C)(C)C)c2ccc(CO)cc2)cc1</smiles><smiles>OCc1ccc(O)cc1</smiles><smiles>CCOC(=O)C(=O)Oc1ccc(I)cc1</smiles><smiles>Oc1ccccc1</smiles>

$\mathrm{CO}_{2}$

Proline oligomer

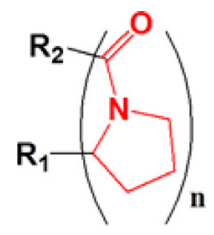<smiles>[R]C(=O)N1C2CC3CC(C2)C([R])(C)C1C3</smiles><smiles>O=CO</smiles><smiles>[R16]NC(=O)C1CCCC1C([R])=O</smiles>
$\mathrm{H}_{2} \mathrm{O}+\mathrm{CO}_{2}$
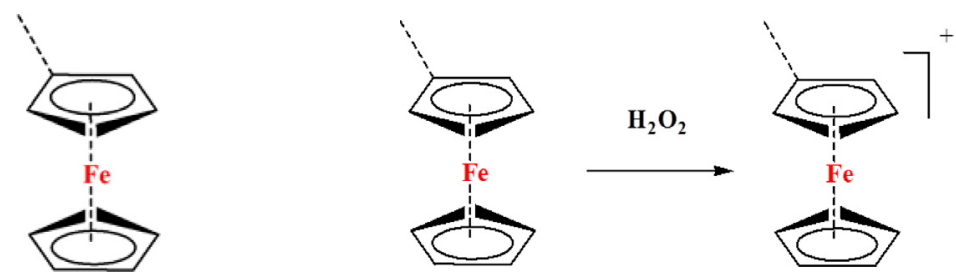

Ferrocene

for drug delivery systems have been developed and have achieved superior and encouraging therapeutic effects over traditional drugs (Lee S. H. et al., 2013; Lou et al., 2015; Saravanakumar et al., 2017; Owen et al., 2018). In this review, we discuss current progress in ROS-responsive polymers for drug delivery, including the types of ROS-responsive polymers and the advantages of application of different ROS-responsive polymers, which is determined by structural characteristics. Further, we describe the design of molecular structures of these ROS-responsive polymers. Finally, we propose future 


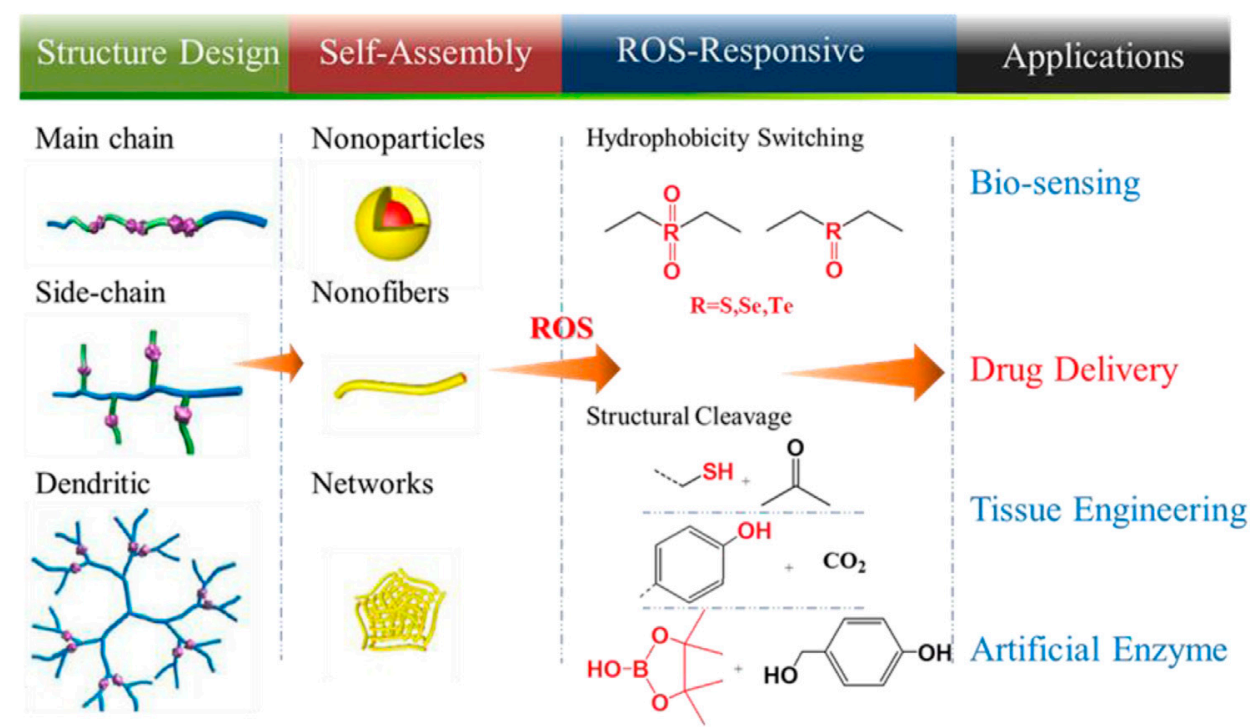

FIGURE 1 | Structure design and technological process of ROS-responsive polymers for drug delivery systems (Hu et al., 2020). Copyright 2020, the American Chemical Society.

perspectives and the trends in the development of ROSresponsive polymers for drug delivery.

\section{REACTIVE OXYGEN SPECIES-RESPONSIVE POLYMERS FOR DRUG DELIVERY}

ROS is a biochemical term used to describe the chemical species formed from incomplete reactions with oxygen (D'Autreaux and Toledano, 2007; Nosaka and Nosaka, 2017). ROS mainly include hydrogen peroxide $\left(\mathrm{H}_{2} \mathrm{O}_{2}\right)$, superoxide $\left(\mathrm{O}_{2} \bullet\right)$, hydroxyl radical $(\bullet \mathrm{OH})$, peroxynitrite $(\mathrm{ONOO})$, singlet oxygen $\left({ }^{1} \mathrm{O}_{2}\right)$, and hypochlorite (OCI) (Gligorovski et al., 2015; Hayyan et al., 2016). ROS play a crucial role in living organisms, including the modulation of protein function, production of several hormones, regulation of cell signaling, and mediation of inflammation. However, overproduction of ROS could give rise to oxidative stress leading to serious damage of cells associated with different diseases, such as cancer (Liu H. et al., 2018), neurodegenerative diseases (Barnham et al., 2004), and inflammation (Fraisl et al., 2009).

ROS are an important feature distinguishing pathological from healthy tissues. ROS are overexpressed in diseased cells, and this property has been exploited to develop ROS-responsive drug carriers for targeted therapy (Chen X. et al., 2016; Deng et al., 2017; Dharmaraja, 2017; Lu et al., 2017). Different types of ROS-responsive polymer carriers had been explored, including thioether-containing polymers, poly(thioketal), selenium/tellurium containing polymers, arylboronic acid/estercontaining polymers, aryl oxalate esters, and poly(proline) (Cheng et al., 2011; Chen Y. et al., 2016; Xu et al., 2016; Luo et al., 2018; Sun et al., 2018; Xu et al., 2018b; Sun et al., 2019; Eleftheriadou et al.,
2020; Liu et al., 2020). These ROS-responsive polymers usually break chemical bonds and/or lead to transformations from hydrophobic to hydrophilic phases, favoring the release of carrier drugs.

The chemical structure and the molecular weight determine the physical properties of polymers and include the glass transition temperature $\left(T_{g}\right)$, solubility, thermal stability, degree of crystallinity, and physical properties. Therefore, the design of a polymer is crucial for ROS-responsive polymers to ensure controlled release of carrier drugs. For example, the hydrophobicity of a polymer is normally increased as the molecular weight increases, while polymers with low molecular weight are always degraded more rapidly. Thus, the release rate of the drugs could be controlled by adjusting the molecular weight of the polymer. From a chemical structure standpoint, the release rate of drugs also could be regulated by increasing the water solubility of polymers through grafting or by copolymerizing hydrophilic chains onto hydrophobic polymers. Overall, when designing the chemical structure of ROS-responsive polymer carriers, the following principles should be considered: (1 good biocompatibility and easy functionalization, (2 solubility in water or in hydrogels is required to increase utilization, and (3 long half-life and does not easily accumulate in the body. The chemical structures and technological process of ROS-responsive polymers are summarized in Table $\mathbf{1}$ (Ye et al., 2019) and in Figure $\mathbf{1}$ (Hu et al., 2020), respectively. Polymers could be designed to integrate ROS-responsive chemical groups into polymers as their main chains or backbone, side chains, or tail chain, and a variety of structures of polymer (the linear copolymer, comb polymers, and dendritic copolymers) are possible. These ROS-responsive polymers could be transformed into nanoparticles, nanofibers, or hydrogels via self-assembly, which are widely used in biosensors, tissue engineering, and as artificial enzymes. An 

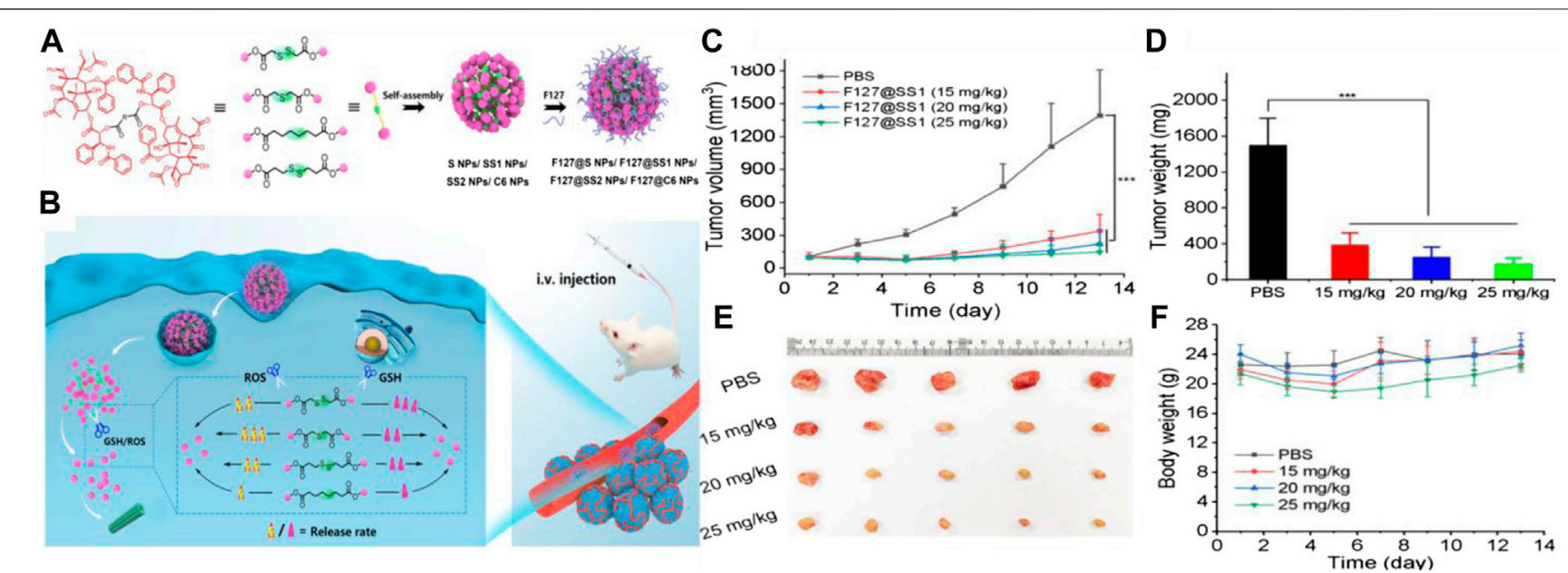

FIGURE 2 | (A) Synthetic routes of the four types of PTX dimer prodrug nanoparticles. (B) Schematic diagram of ROS-and GSH-responsiveness of nanoparticles in tumor cells. (C) Curves of tumor volume treated with different prodrug nanoparticles, respectively. (D) Changes in tumor weights following treatment with different prodrug nanoparticles. (E) Photographs of excised tumors. (F) Body weight of tumor-bearing mice (Wang et al., 2011). Copyright 2020, the American Chemical Society.

important and promising application is ROS-responsive polymer drug carriers.

\section{SULFUR-CONTAINING POLYMERS}

Sulfur is a crucial and fundamental element for all living things. Many amino acids contain a sulfur group, such as cysteine, methionine, homocysteine, and taurine, and some universal enzymes also contained sulfur. Sulfur is an active element of the chalcogen family, which is readily available in nature. It shares two electrons with other elements, forming compounds with oxidation states of $-2,+6,+4,+2$, and +1 . Sulfur is typically nontoxic, and consequently, sulfur-containing polymers for drug delivery have been extensively exploited over the past two decades, mostly because of the abundant polymer structure, the low toxicity, and their biocompatibility.

\section{Thioether-Containing Polymers}

Thioether-containing polymers are one of the most investigated ROS-responsive materials. Thioethers are characterized by phase transition from hydrophobic to hydrophilic induced by ROS. Thioether groups are easily converted into sulfoxide under mild conditions in the presence of oxidative factors at low temperature and may be turned into sulfones under strong oxidative conditions. This oxidation reaction process changes the solubility of the polymer and leads to the decomposition of the nanocarriers and, subsequently, release of the payload ( $\mathrm{Hu}$ and Tirelli, 2012). Thus, thioether-containing polymer phase transition induced by ROS is crucial for targeted drug release. Poly(propylene sulfide) (PPS) is one of the most interesting thioether-containing polymers. It had been extensively studied over the past two decades on account of its specific properties. PPS had a suitable $T_{g}$ and hydrophobic performance, which easily converts into hydrophilic under the microenvironment of the lesion in the presence of elevated ROS. Moreover, $\mathrm{OCl}^{-}$oxidizes
PPS much faster than $\mathrm{H}_{2} \mathrm{O}_{2}$. PPS is mainly oxidized into poly(propylene sulfoxide) by $\mathrm{H}_{2} \mathrm{O}_{2}$, while more sulfone groups are produced following treatment with $\mathrm{OCl}$. In a pioneering study on PPS for drug delivery, Hubbell et al. synthesized an amphiphilic copolymer using poly(ethylene glycol) (PEG) as the hydrophilic block and the PPS as the hydrophobic block. Owing to low $T_{g}$ and oxidative phase conversion, the amphiphilic copolymer vesicles could be further oxidized and destabilized (Napoli et al., 2004). Subsequently, various polymers containing thioether groups composed the main backbone, and the side chains or the tail chains have been developed and synthesized for application in biomedicine and biotherapy for cancer, neurodegenerative diseases, and inflammatory disorders (Yang et al., 2020).

Polymers containing thioether in the main chain have been developed mainly using transfer polymerization, ring-opening polymerization (ROP), and step-growth polymerization. For instance, Walker et al. explored nanoparticles $(<150 \mathrm{~nm})$ composed of PPS-containing thioether inserted in its backbone by ROP (Allen et al., 2011). The nanoparticles were able to undergo phase transition from hydrophobic to hydrophilic, because the polysulfide was transformed into polysulfoxides and polysulfones under ppm levels of $\mathrm{NaOCl}$. The rate of drug release under the oxidizing agent was evaluated, and the authors found that the nanoparticle formation was triggered in the presence of low concentrations of $\mathrm{NaOCl}(200 \mathrm{mM})$ and $\mathrm{H}_{2} \mathrm{O}_{2}$ $(500 \mu \mathrm{M})$. These nanoparticles containing thioether in the main chain were promising constructs for controlled encapsulation and release of a variety of hydrophobic drugs. A hydrophobic anticancer drug 7-ethyl-10-hydroxyl-camptothecin (SN38) and a hydrophilic oligomer of ethylene oxide oligo (ethylene glycol) (OEG) were produced using the thioether chain connection (OEG-2S-SN38). The drug loading rate of OEG-2S-SN38 nanocapsules could achieve $35 \mathrm{wt} \%$. The nanocapsules quickly collapsed, and more than $80 \%$ of the SN38 loaded was released within $15 \mathrm{~min}$ in the presence of $5 \mathrm{mM} \mathrm{H}_{2} \mathrm{O}_{2}$. The ROS sensitivity 

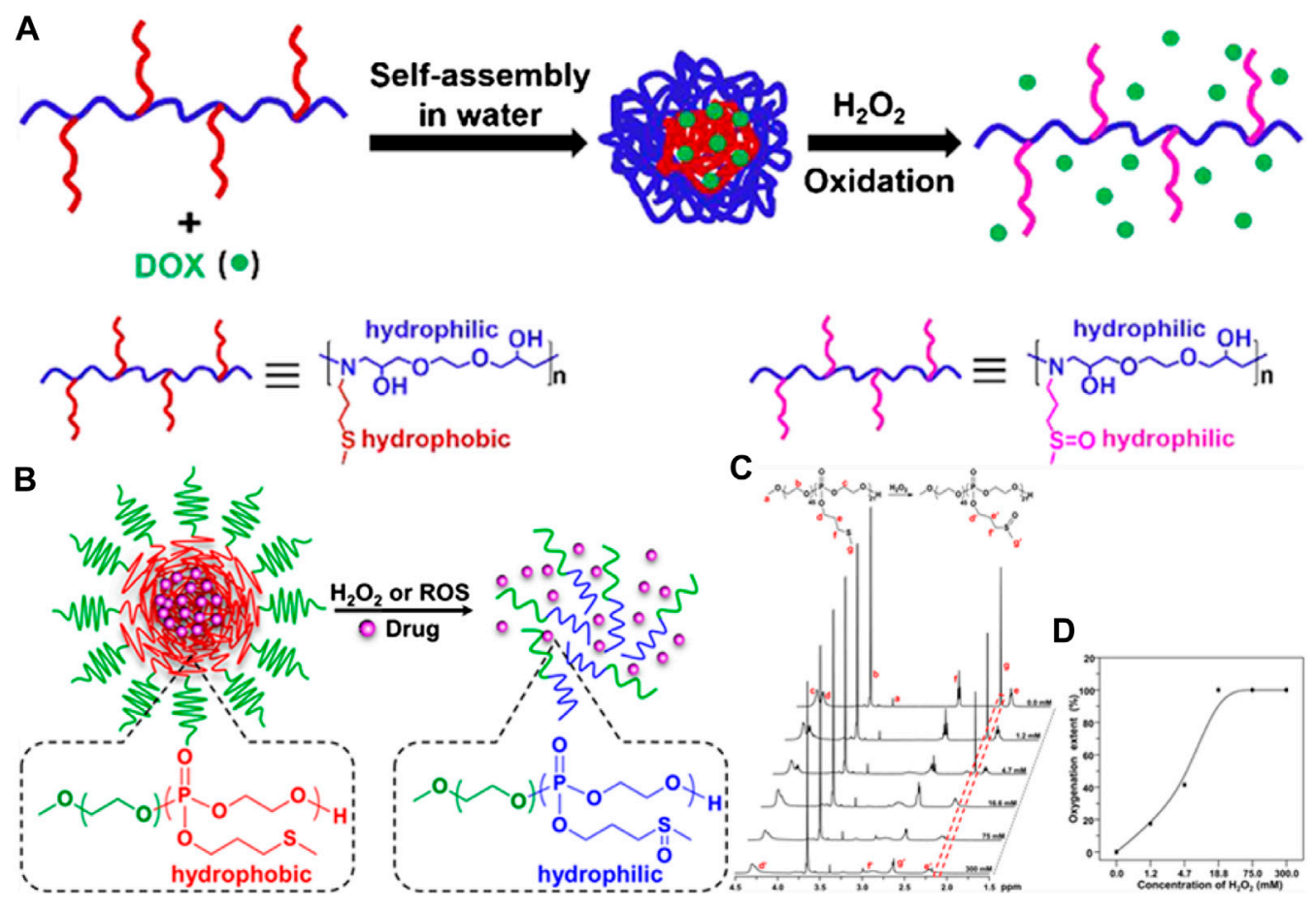

C

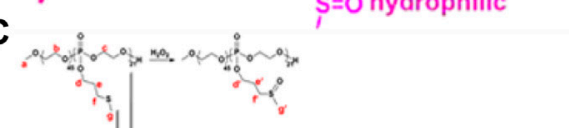

D

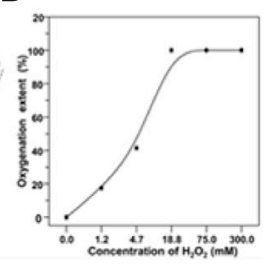

FIGURE 3 | (A) The chemical structure of thioether side chain polymer carriers and the drug release behavior of DOX-loaded P(MSPA- $a$-EG) micelles (Wang et al., 2019). Copyright 2019, the American Chemical Society. (B) Schematic illustration of thiother-pendant monomers MSPEP for polymerization of ROS-responsive carriers (C) $1 \mathrm{H}$ NMR spectra of mPEG-b-PMSPEP carried out following oxidation in the presence of different $\mathrm{H}_{2} \mathrm{O}_{2}$ concentrations. (D) Oxygenation degree of mPEG-bPMSPEP in the presence of different $\mathrm{H}_{2} \mathrm{O}_{2}$ concentrations (Wang et al., 2019). Copyright 2019, the American Chemical Society.

indicated that polymers containing thioether in the main backbone could act as an ideal drug delivery carrier (Wang et al., 2013). Lo et al. developed ROS and glutathione (GSH) dual redox-responsive micelles, which underwent thioether bond oxidation in the presence of high ROS levels, and the disulfide structure was cleaved in the presence of GSH (Chiang et al., 2015). $\mathrm{Hu}$ et al. also systematically studied the sensitivity of thioether and disulfide structure under higher expression of GSH and ROS in cancer cells. Four types of paclitaxel (PTX) dimers with different linkers were synthesized through esterification, as shown in Figure 2. The author's results indicated that the thioether bond had a higher ROS sensitivity because of the lower negative potential, and the thioether bond could be readily oxidized in the presence of $10 \mathrm{mM} \mathrm{H}_{2} \mathrm{O}_{2}$ in comparison to the disulfide bond. Conversely, the disulfide bond exhibited higher GSH sensitivity due to the presence of - $\mathrm{SH}$, and an exchange reaction occurred. The study provided a design rationale for ROS and GSH dual-responsive prodrugs or carriers using thioether bond and disulfide bonds, which underlined the significance of ROS polymers containing the thioether backbone structure (Wang et al., 2011).

Polymers with thioether side groups could present more diversified structures by the introduction of a variety of thioether monomers, such as 3-(methylthio)-propylamine (MSPA) (Wang G. C. et al., 2019), 2-(methylthio)-ethyl glycidyl ether, and 3-(methylthio)propyl ethylene phosphate (MSPEP) (Wang J. H. et al., 2019). When the thioether in the side chains reacts with ROS, the polymer's main chain is not damaged and maintains the structure of the polymer's backbone chain. Therefore, thioether-containing polymers in side chains were often used as multifunctional drug carriers. Huang et al. synthesized an amphiphilic polymer (P(MSPA- $\alpha-E G)$ ) containing thioether in the side chains through an amine-epoxy click reaction at room temperature. The anticancer drug doxorubicin (DOX) could be encapsulated by P(MSPA- $\alpha-E G)$ micelles with a diameter of approximately $151 \mathrm{~nm}$, and the DOX load and loading efficiency were 4.90 and $9.81 \%$, respectively. DOX could be released rapidly from DOX-loaded $\mathrm{P}$ (MSPA- $\alpha-E G)$ micelles in the presence of $20 \mathrm{mM} \mathrm{H}_{2} \mathrm{O}_{2}$, and the cumulative release of DOX could reach up to $55.6 \%$. The chemical structure of polymer carriers and the drug-releasing behavior of the DOX-loaded P(MSPA- $\alpha-E G)$ micelles are shown in Figure 3A (Wang et al., 2019). Wang et al. synthesized an amphiphilic copolymer (mPEG-b-PMSPEP) with thioether side groups using ROP. The photosensitizer chlorin e6 (Ce6) and anticancer drug PTX were successfully packaged into mPEG-b-PMSPEP nanoparticles. The mPEG-b-PMSPEP nanoparticles were responsive to ROS generated by light and a photosensitizer. Further, the encapsulated mPEG-b-PMSPEP nanoparticles underwent oxidation in the presence of ROS generated by light irradiation, achieving an irradiationaccelerated PTX release. The chemical structure of mPEG-bPMSPEP and the encapsulated MPEG-b-PMSPEP nanoparticles are shown in Figure 3B; Wang et al., 2019. In addition, the drug 

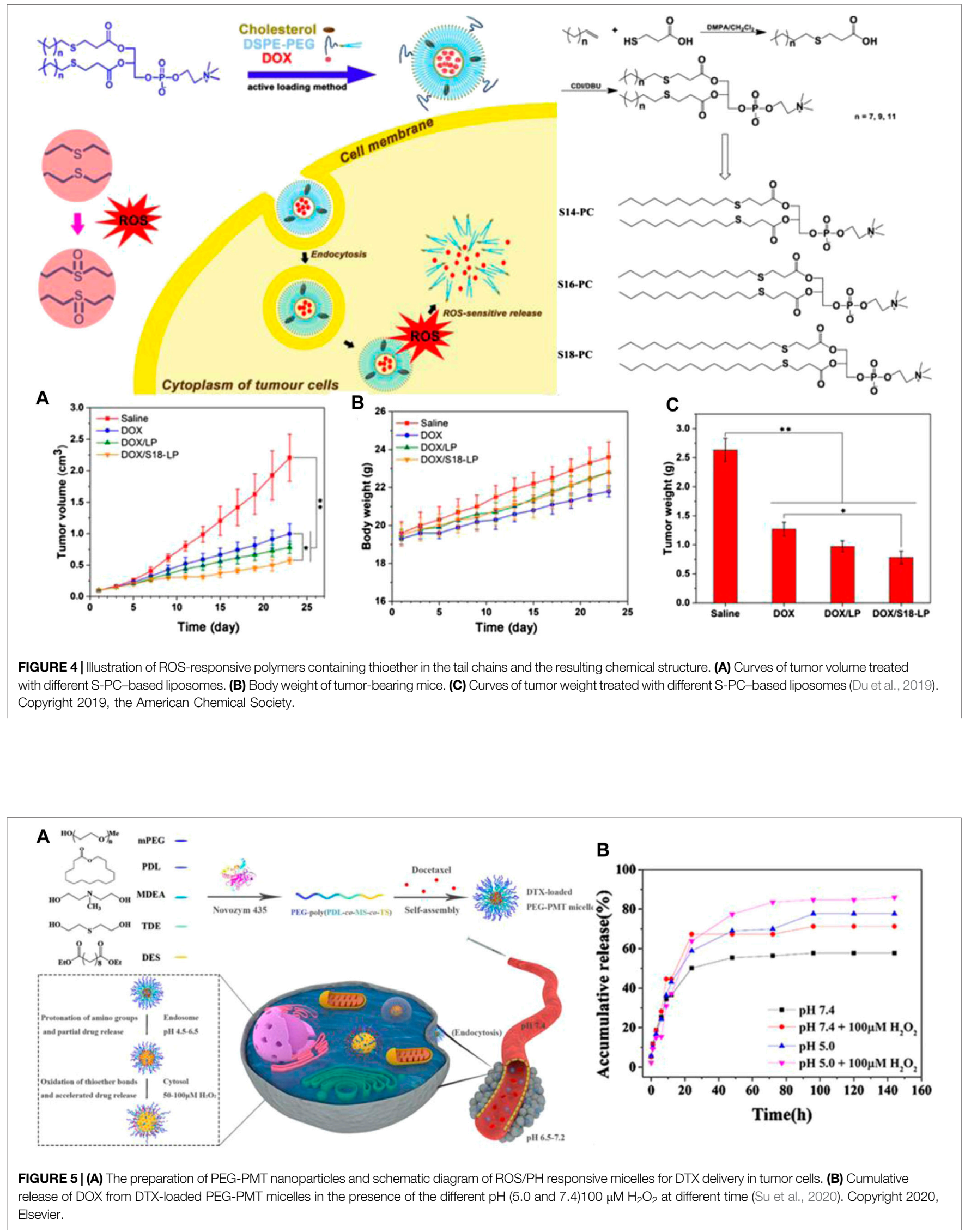

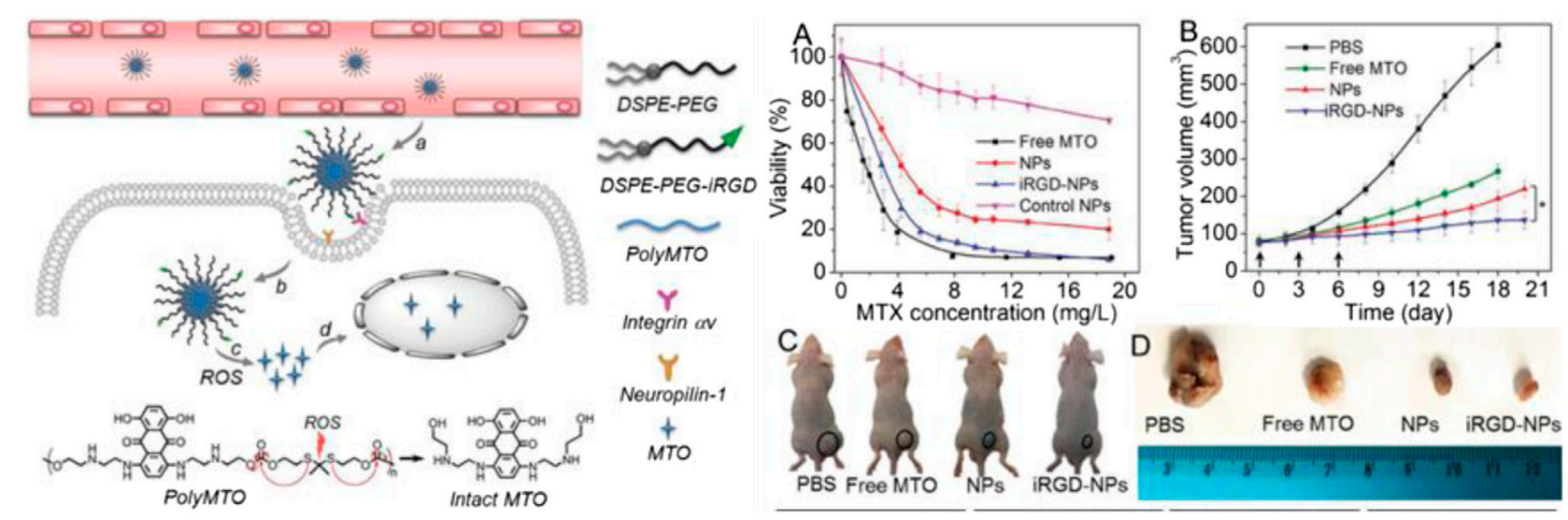

FIGURE 6 | Schematic diagram of the mechanism for release of intact anticancer drug molecules mitoxantrone (MTO) and the chemical structure of polyMTO. (A) Cytotoxic effects induced by different polyMTO-based nanoparticles. (B) Curves of tumor volumes following treatment with different prodrug polyMTO-based nanoparticles. (C) Photograph of tumor-bearing mice; tumors are indicated by circles. (D) Photograph of tumor volume after treatment with PBS and various prodrug polyMTO-based nanoparticles (Xu X. et al., 2017). Copyright 2017, John Wiley and Sons.

carrier can be modified to contain thioethers in polypeptide side chains (Fu et al., 2014).

Polymers containing thioether in the tail chains have also been developed. The chain length of polymer tails is relatively easy to control when the thioether linker is used in end-capping the polymer terminal. This construct also maintains the backbone function intact as well as the thioether in the side chain. Li et al. synthesized $\mathrm{S} 14-\mathrm{COOH}, \mathrm{S} 16-\mathrm{COOH}$, and $\mathrm{S} 18-\mathrm{COOH}$ using olefin and thiohydracrylic acid using the click reaction as the first step (Figure 4). The second step involved the preparation of three thioether-containing phosphatidylcholines (S-PCs) with different tails, and S14-COOH, S16-COOH, and $\mathrm{S} 18-\mathrm{COOH}$ were used as end-capping agents by esterification reactions. The phase transition temperature and self-assembly ability were determined by the structures of the different length of the tail chains for the S-PCs. Further, S-PC-based liposomes (S-LPs) have been used for ROS-responsive controlled release of DOX. The testing of the anticancer effects including changes in tumor volume, body weight, and tumor weight in vivo showed that the polymer containing thioether in the tail chains had tremendous potential as a ROS-responsive polymer drug delivery construct for tumor therapy (Du et al., 2019).

Various multiple-responsive systems can be achieved when thioether groups are combined with other stimuli-responsive
A

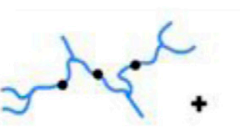<smiles>C1CCCCC1</smiles>

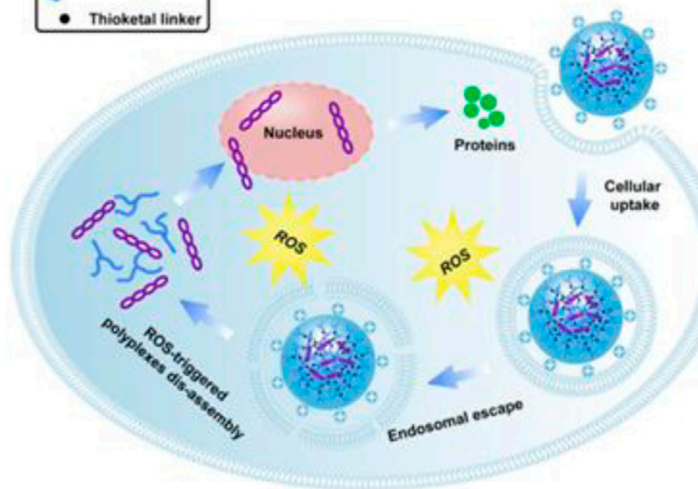

B

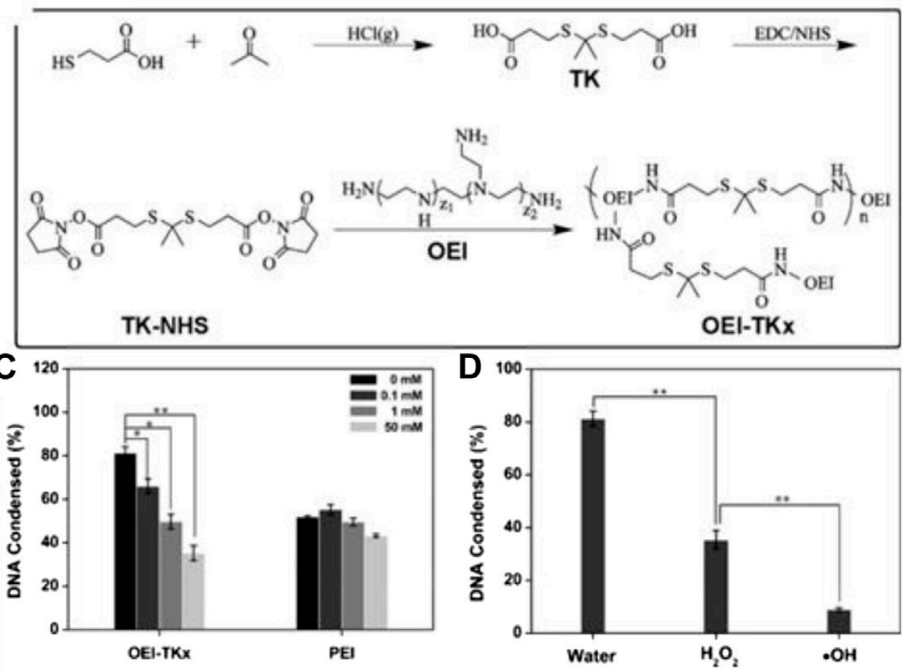

FIGURE 7 | (A) Schematic diagram of OEI-TKX/DNA polyplexes for gene delivery. (B) Synthetic routes of the TK-containing cross-linkers and OEI-TKx. (C) Percentage of DNA condensation with different $\mathrm{H}_{2} \mathrm{O}_{2}$ concentrations; the gene release efficiency of OEl-TKX/DNA polyplexes was determined by the EtBr exclusion assay. (D) Graph of ROS-responsive DNA release from OEI-TKX/DNA under various conditions (Zhang et al., 2019). Copyright 2019, the American Chemical Society. 

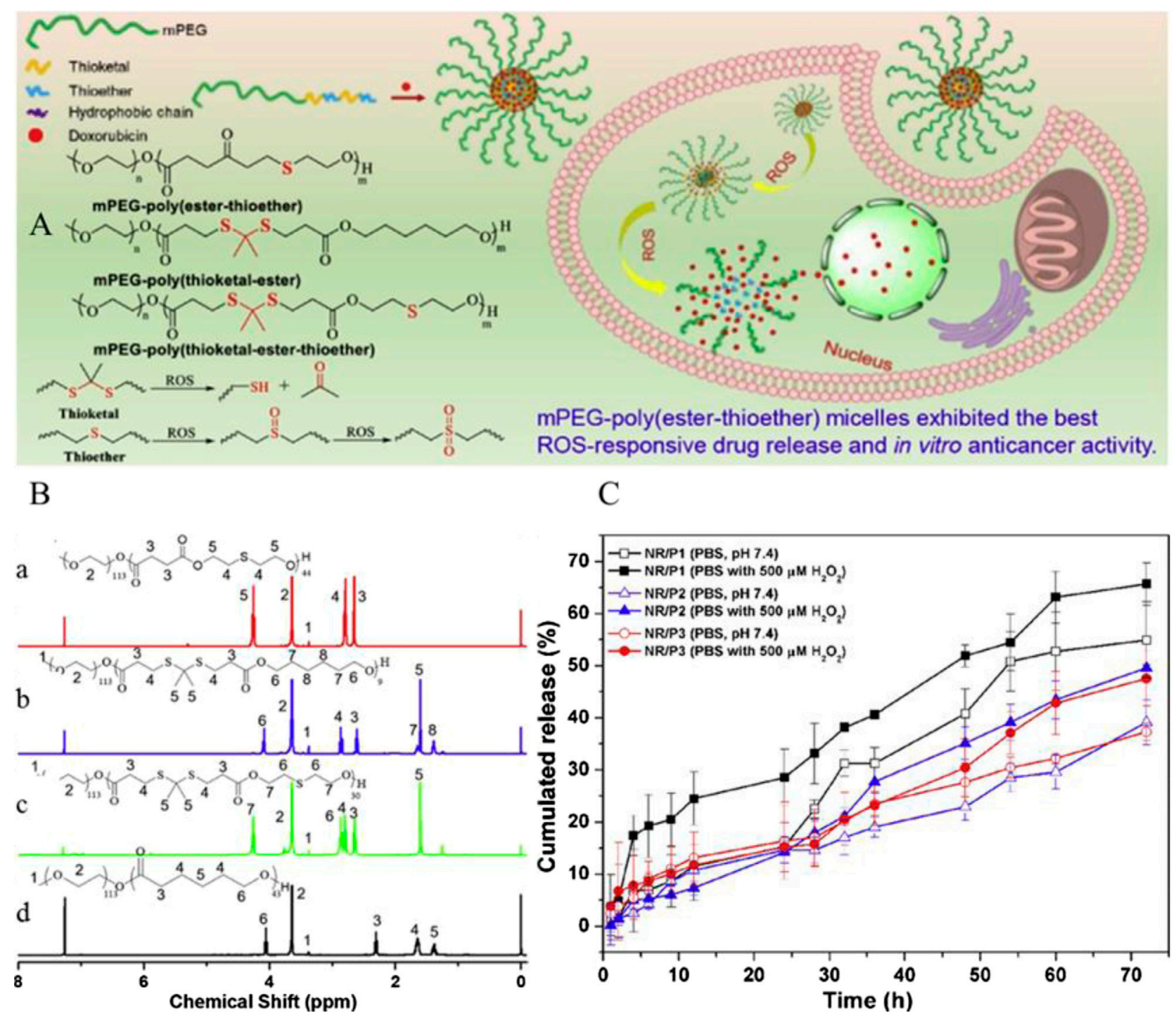

FIGURE 8 | (A) Schematic diagram of ROS-responsive nanoparticles and chemical structure of mPEG-poly(ester-thioether), mPEG-poly(thioketal-ester), and mPEG-poly(thioketal-ester-thioether). (B) Structures of mPEG-poly(ester-thioether) (a), mPEG-poly(thioketal-ester) (b), mPEG-poly(thioketal-ester-thioether) (c), and mPEG-b-PCL (d) were confirmed by $1 \mathrm{HNMR}$ spectra using $\mathrm{CDCl}_{3}$ as the solvent. (C) Graph of the DOX-loaded P1, $\mathrm{P} 2$, and P3 micelle drug release in $500 \mu \mathrm{M} \mathrm{H} \mathrm{O}_{2}\left(\mathrm{Xu}_{\mathrm{H}}\right.$ et al., 2019). Copyright 2019, Elsevier.

functional groups, such as ROS/temperature (Xiao et al., 2015), ROS/PH (Su et al., 2020), ROS/light, and GSH/ROS (Yin et al., 2020). For example, Chen et al. developed ROS/temperature dual-responsive polymer carriers (PEG-EDT) via thiolene polymerization of poly(ethylene glycol)diacrylate (PEGDA) and 1,2-ethanedithiol (EDT) monomers. PEG-EDT exhibited a reversible temperature-induced phase transition due to, obviously, synergy between the hydrophobic interaction of the thioether and the dehydration of PEG. Additionally, the PEG-EDT copolymers also possessed ROS-responsive behavior due to the presence of the thioether groups in the backbone chain (Xiao et al., 2015). Liu et al. synthesized pH/ROS dual-responsive biodegradable polymer carriers (PEG-PMT) via lipase-catalyzed copolymerization. The PEG-PMT nanoparticle sizes increased sharply in the presence of oxidative factors and the acidic environments due to the contribution of protonation of the thioether groups and the oxidation of the amino groups. DOX could be released rapidly from DTX-loaded PEG-PMT micelles at $\mathrm{pH} 5.0$ and in the presence of $100 \mu \mathrm{M} \mathrm{H}_{2} \mathrm{O}_{2}$ after $144 \mathrm{~h}$. The cumulative release of DOX, over $85 \%$ of the anticancer drug load, is shown in Figure 5B; Su et al., 2020). These experimental results demonstrated that multipleresponsive polymer carriers can be modified by functional groups to ensure more efficient controlled release of drug dosage forms for targeted drug delivery systems than singleresponsive polymer carriers.

Taken together, thioether-containing polymers provide a compelling approach for loading hydrophobic cytotoxic drugs 
and improving the efficiency of targeted drug delivery for the treatment of cancer and inflammatory diseases. Meanwhile, exploiting different structural designs of thioether-containing polymers will likely have strong application potential.

\section{Poly(thioketal)}

Unlike the thioether-containing polymer described above, the application of poly(thioketal) exploits the characteristic thioketal (TK) bond that can be cleaved following ROS induction to produce acetone and two other thiol-containing fragments, which then lead to polymer chain scission and breakdown. The chemical structure of TK is very similar to that of the thioether group (see Table 1 for details). Previous studies have shown that TK undergoes oxidative reactions with several kinds of ROS, including $\mathrm{H}_{2} \mathrm{O}_{2}, \bullet \mathrm{OH}$, and $\mathrm{O}_{2} \bullet$ (Shim and Xia, 2013), which implies that the TK bond could be used as the functional group in ROS-responsive polymers for drug delivery. More importantly, the by-product of TK cleavage could be metabolized easily (Zhang Y. et al., 2017). Therefore, TK is an important component for the design of ROS-responsive polymers.

TK-containing polymers in the main chain can be synthesized by direct condensation polymerization using thiols (Natalia et al., 2019). Xu et al. prepared a polyprodrug (polyMTO) with a ROSresponsive TK group by condensation polymerization for targeted cancer therapy. PolyMTO nanoparticles had the advantages of high drug loading, longer blood circulation, targeted drug delivery, and release of intact anticancer drug molecules such as mitoxantrone (MTO). These advantages were attributed to the ability of TK-containing linkage to be cleaved in the presence of ROS. The experimental data in vivo showed that the polyMTO-based nanoparticles had significant therapeutic effects on inhibiting tumor cell growth (see Figure 6B for details; Xu X. et al., 2017). He et al. also synthesized a poly(ester-thioacetal) copolymer and introduced the functional group thioacetal and cinnamaldehyde (CA) by condensation polymerization. When the thioacetal bond cleaved in the tumor microenvironment, the CA from the polymer chain was released to prompt mitochondria to regenerate ROS. The process synergistically increased the anticancer treatment efficiency and achieved high-efficiency drug delivery (Xu et al., 2018a).

TK-containing polymers in the side chain were synthesized by various TK-containing cross-linkers instead of direct condensation polymerization using thiols. Two main reasons explain why monomers containing thiols were easily oxidized and why the condensation polymerization method was often unable to prepare high molecular weight and narrow the polydispersity of polymers. This method that is often adopted involves various TK-containing cross-linkers to be synthesized and then used to synthesized TK-containing polymers. The advantage of the TK cross-linker is that it prolongs blood circulation time due to improvement of stability and accelerates drug release in response to the excess ROS found in the tumor microenvironment (Zhang Y. et al., 2017). Gu et al. synthesized TK-containing cross-linkers using 3mercaptopropionic acid and acetone as the first step, and then a water-soluble polymer (OEI-TKx) was synthesized via TK cross-linking. The synthetic route is shown in Figure 7B. The OEI-TKx degradation performance was investigated upon exposure to $100 \mathrm{mM} \mathrm{H}_{2} \mathrm{O}_{2}$ containing $1.6 \mu \mathrm{M} \mathrm{CuCl}_{2}$ at $37^{\circ} \mathrm{C}$. The molecular weight dropped significantly, and the level of degradation was consistent with that of oligoethylenimine (OEI) without TK following simultaneous exposure to $400 \mathrm{mM} \mathrm{H}_{2} \mathrm{O}_{2}$ containing $1.6 \mu \mathrm{M} \mathrm{CuCl}_{2}$. The results demonstrated that OEITKx had the ability to respond to ROS, in which the TK group played an important role. The OEI-TKx/DNA polyplexes were also developed to produce higher gene release efficiency. The gene release efficiency of OEI-TKx/DNA polyplexes was detected using the ethidium bromide (EtBr) exclusion assay, whereby the percentage of DNA condensation decreased with the sharp increase in $\mathrm{H}_{2} \mathrm{O}_{2}$ concentration, as shown in Figure 7C. Thus, the unique properties of TK linkages may have potential application as stimulus-responsive materials for gene delivery (Zhang et al., 2019).

Furthermore, TKs in combination with thioether have also been developed for drug delivery. Poly(thioketal) and thioethercontaining polymers are both sulfur-containing ROS-responsive polymer carriers, but as mentioned above, they exhibit completely different ROS-responsive mechanisms. If the TK bonds and thioether bonds exist together linked by covalent bonds on the same polymer chain as functional groups, the polymer may have an enormous effect on drug release. Xu et al. synthesized an amphiphilic copolymer micelle mPEG-poly(ester-thioether) (P1) using thiodiglycol (TDG) and methoxy poly(ethylene glycol) (mPEG), mPEG-poly(thioketal-ester) (P2), and mPEG-poly(thioketal-ester-thioether) (P3). Similar to P1, mPEG-b-PCL (P4) had also been synthesized in order to compare the properties of the three ROS-responsive polymers. The chemical structures and the 1H NMR spectra of the copolymers are presented in Figure 8. The drug loading capacity of the DOX-loaded P1, P2, P3, and P4 micelles was evaluated, and the three ROS-responsive polymer micelles all exhibited better drug loading efficiency than P4 micelles without ROS sensitivity. P3 micelles presented the best drug loading efficiency with drug loading content and the encapsulation efficiencies of 13.7 and $68.35 \%$, respectively. The drug release of the DOX-loaded P1, P2, and P3 micelles was inspected in the presence of $500 \mu \mathrm{M} \mathrm{H}_{2} \mathrm{O}_{2}$ (Figure 8C). The DOX-loaded P1 micelle exhibited the fastest drug release rate, and the cumulative release rates reached to $65 \%$ (Xu et al., 2019). Furthermore, TK bonds were stable under acidic, alkali, or protease conditions. Therefore, TK-containing polymers were optimal for therapeutics targeting inflamed tissues in the intestine (Wilson et al., 2010).

\section{SELENIUM-CONTAINING POLYMERS}

Selenium is an essential element in the human body and plays a significant role in protecting cells from oxidative damage. The lack of selenium in the human body may lead to Keshan disease and depression. Selenium has a higher atomic number and lower electronegativity than sulfur; thus, selenium-containing polymers have lower bond energy than sulfur-containing 


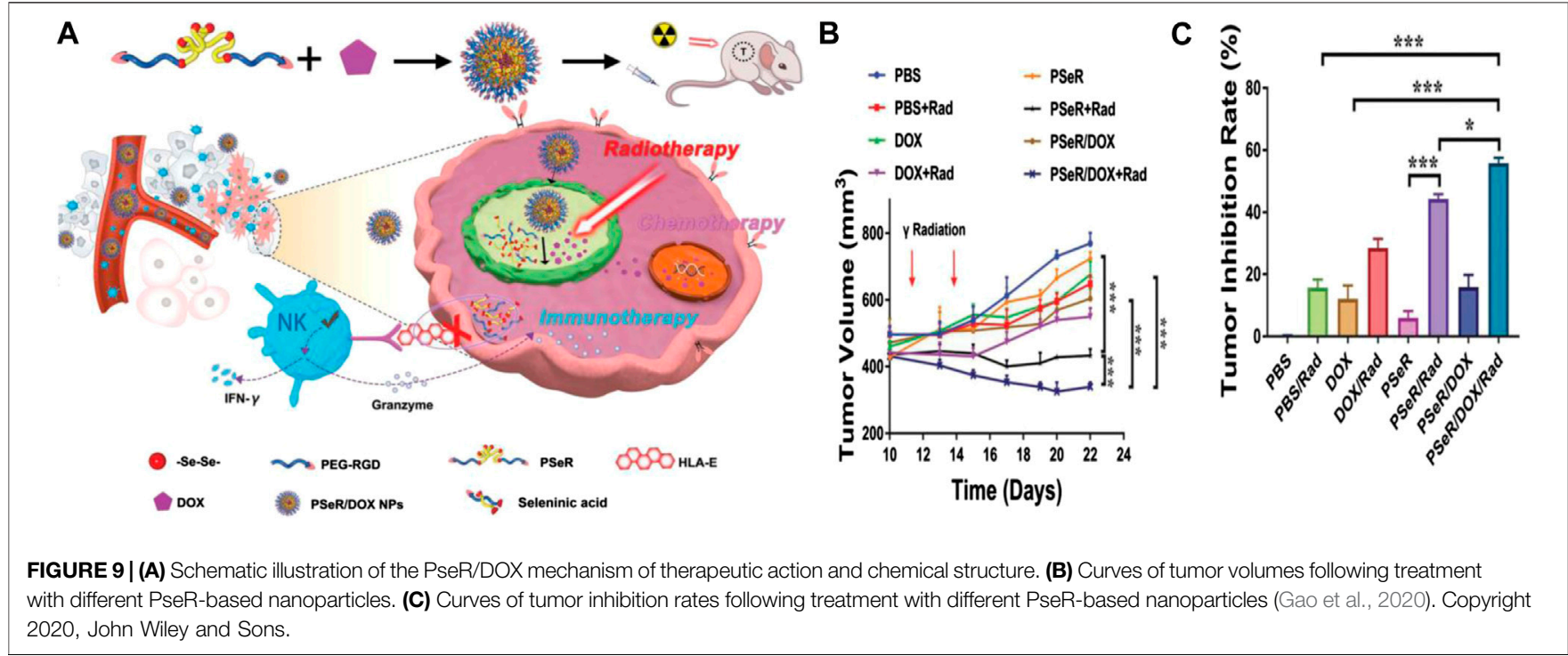

polymers (C-Se bond $244 \mathrm{~kJ} / \mathrm{mol}$, Se-Se bond $172 \mathrm{~kJ} / \mathrm{mol}$, C-S $272 \mathrm{~kJ} / \mathrm{mol}$, and S-S $240 \mathrm{~kJ} / \mathrm{mol}$ ). Selenium-containing polymers are a promising biomaterial for targeted drug delivery due to their more sensitive response to ROS. Selenide can be oxidized to selenoxides and selenones, having a mechanism of action similar to thioether, and oxidation leads

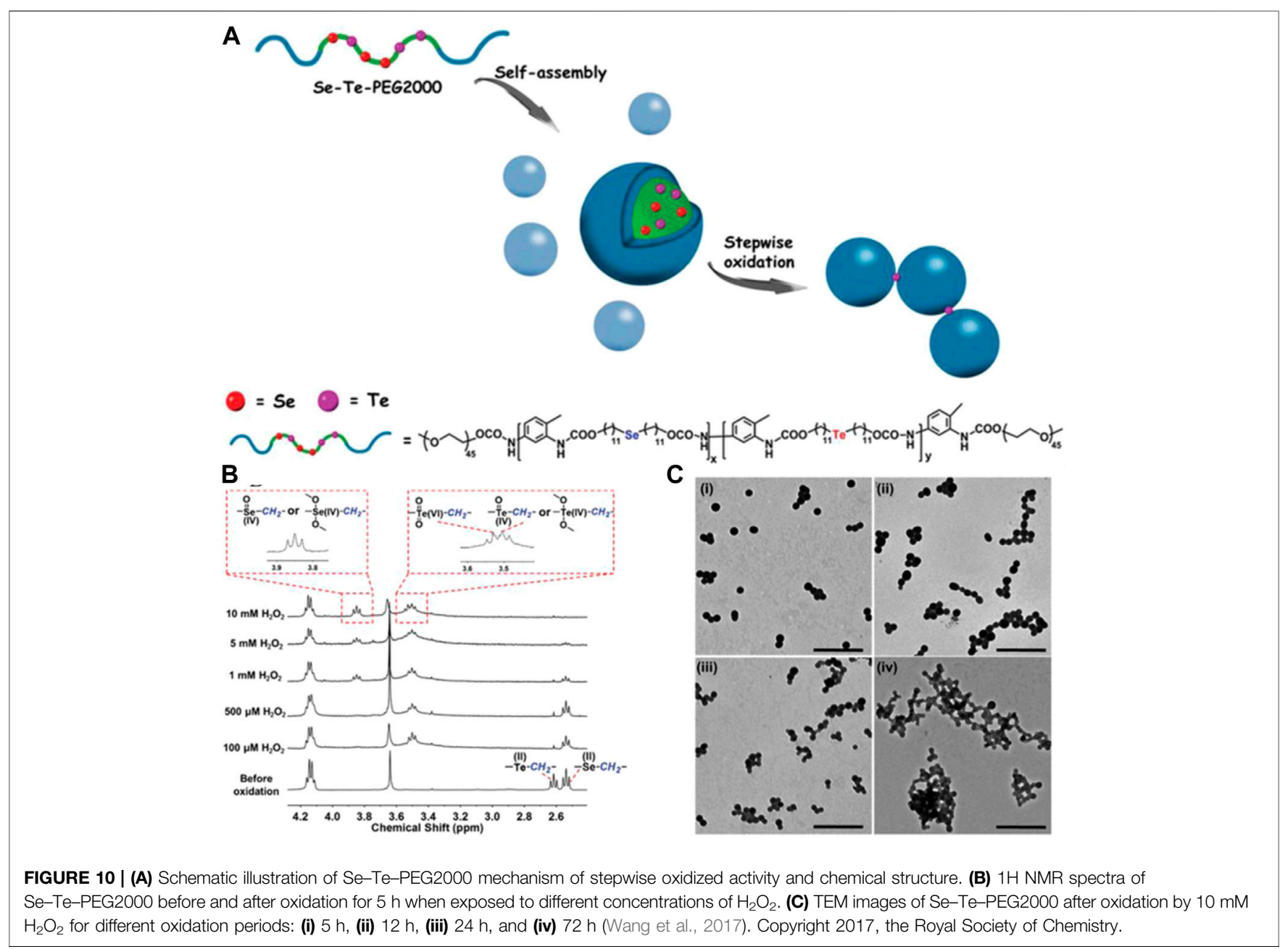


to phase transition from hydrophobic to hydrophilic. Diselenide bonds can be oxidized to seleninic acid and then are reduced to selenol and ultimately cracked, which is a mechanism of action that is similar to that of disulfide bonds. The only difference is that selenium-containing polymers possess higher sensitivity to oxidants than sulfur-containing polymers (Xu et al., 2013). Therefore, selenium-containing polymers are more widely used in environments with lower ROS concentrations (Liu et al., 2012).

The interest in the synthesis of selenium-containing polymers had been limited for a long time, as selenide and diselenide bonds were unstable in the presence of oxygen and given the poor solubility of the polymer. This view changed in 2010, when a groundbreaking study by Xu and Zhang et al. (Ma et al., 2010b) discovered that solubility could be increased by introducing the diselenide group into a diol structure. Amphiphilic diselenidecontaining polyurethane (PUSeSe) was synthesized using toluene diisocyanate (TDI) and diselenide-containing diols via stepwise polymerization. Since then, many copolymers have incorporated selenium-containing polymers and have resulted in the synthesis of ROS-responsive polymer carriers. Sun et al. developed a series of selenium-containing polymers by coupling reactions such as the amphiphilic di-block polymer (MPEG-IPDI-Se-Se-IPDI-PPG), which was synthesized using PEG, di(1-hydroxyethylene) diselenide, monomethyl ether (mPEG), and polypropylene glycol (PPG) via four coupling reactions (Sun et al., 2013a) and an amphiphilic triblock polymer (Se-Se-tri-ABP) (Sun et al., 2013b). Selenium-containing macrocyclic monomers have been developed to synthesize selenium-containing polymers as the backbone via living ring-opening polymerization (ROP) in the presence of lipase CA (Liu T.-I. et al., 2018; Wei et al., 2018). Subsequently, $\mathrm{Xu}$ and Zhang et al. developed a series of ROSresponsive selenium-containing polymers for drug delivery. According to the position of the selenide and diselenide bonds in the polymer chain, the polymer could be divided into polymers containing selenium in the main chain ( $\mathrm{Ma}$ et al., 2010a; Tan et al., 2012; Xia et al., 2017; Zhou et al., 2017), in the side chain (Han et al., 2010; Ren et al., 2012), and in dendritic selenium-containing polymers (Xu et al., 2006; Fu et al., 2012; Li et al., 2016).

In addition, to reduce side effects, selenium-containing polymers were adopted for application in ROS- and lightresponsive drug delivery systems for chemotherapy and radiotherapy ( $\mathrm{Li}$ T. Y. et al., 2020). The light sources include red light (Han et al., 2013), visible light (Ren et al., 2013; Sun et al., 2017), and $\boldsymbol{\gamma}$-radiation (Ma et al., 2011). Recently, Xu et al. synthesized PSeR/DOX, a diselenidecontaining polymer (PseR), using 11, 11'-diselanediylbis(undecan-1-ol) (DseOH), RGD, and PEG through stepwise polymerization. PseR nanoparticles could be oxidized to seleninic acid when treated with 5 and $2.5 \mathrm{~Gy}\left(1 \mathrm{~Gy} \mathrm{~min}^{-1}\right)$ $\gamma$-ray radiation, which were much weaker levels than the normal cancer therapy doses given in vivo. The release of DOX was greatly improved as ROS and $\gamma$-radiation exerted a synergistic effect during this chemical process. The PseR/ DOX formulation could effectively inhibit the tumor growth, tumor volume, and growth rates (Figure 9; Gao et al., 2020). The preparation had high application potential to achieve radiotherapy, chemotherapy, and immunotherapy simultaneously, and thus, selenium-containing polymers have also been used as ROS-responsive polymer carriers because of their high sensitivity for ROS in seleniumcontaining polymers (Xia et al., 2018; Sun et al., 2020).

\section{TELLURIUM-CONTAINING POLYMERS}

Tellurium is another important element in the chalcogen family and is an unnecessary and potentially toxic element in human body. Tellurium is very rare in nature partly due to its high atomic number. Tellurium-containing polymers possess higher sensitivity to ROS than selenium-containing polymers. Tellurium-containing polymers may find potential application as ROS-eliminating materials, and not as agents for ROSresponsive delivery of drugs under physiological environment (Cao et al., 2014; Wang et al., 2020).

The synthesis of polymers containing tellurium is similar to that of polymers containing selenium. Xu et al. have carried out most of the related research on tellurium-containing polymers. The group has reported that co-assembly via tellurium-containing molecules and phospholipid exhibits ultrasensitive ROS-responsive properties and biocompatibility. The co-assemblies respond to the ROS concentration present in physiological conditions $(100 \mu \mathrm{M}$ $\mathrm{H}_{2} \mathrm{O}_{2}$ ) due to tellurium (Wang et al., 2015). Linear tellurium-containing polymers (PEG-PUTe-PEG) are responsive to $100 \mu \mathrm{M} \mathrm{H}_{2} \mathrm{O}_{2}$ and can be coupled with radiation therapy. The ROS produced by $\gamma$-ray radiation (2 Gy) may trigger phase transition of the PEG-PUTe-PEG (Cao et al., 2015). Tellurium-containing hyperbranched polymers have also been synthesized, and the influence of the degree of cross-linking degree on the ROS-responsive behavior was investigated. Hyperbranched polymercontaining tellurium swell upon exposure to ROS concentrations in physiological conditions $\left(100 \mu \mathrm{M} \mathrm{H}_{2} \mathrm{O}_{2}\right)$ in an aqueous environment, and this property could be used to eliminate excess ROS levels (Fang et al., 2015).

In addition, an amphiphilic multi-hierarchical responsive polymer (Se-Te-PEG2000) comprising the hydrophobic blocks selenium- and tellurium-containing polyurethane and the hydrophilic blocks PEG mono-methyl ethers has also been designed and synthesized. Se-Te-PEG2000 was synthesized using di-(1-hydroxylundecyl) selenide (MseOH), TDI, and di-(1-hydroxylundecyl) telluride $(\mathrm{MteOH})$. The chemical structure and the $1 \mathrm{H}$ NMR spectra of Se-Te-PEG2000 are shown in Figure 10. Hierarchical responsive properties of Se-Te-PEG2000 were derived from the selenium, while tellurium had different sensitivities to oxidation. Thus, Se-Te-PEG2000 could undergo stepwise oxidization by tuning the concentration of the oxidant (chemical methods) or by tuning the voltage during exposure to electrochemical stimuli (electrochemical methods) (Wang et al., 2017). 


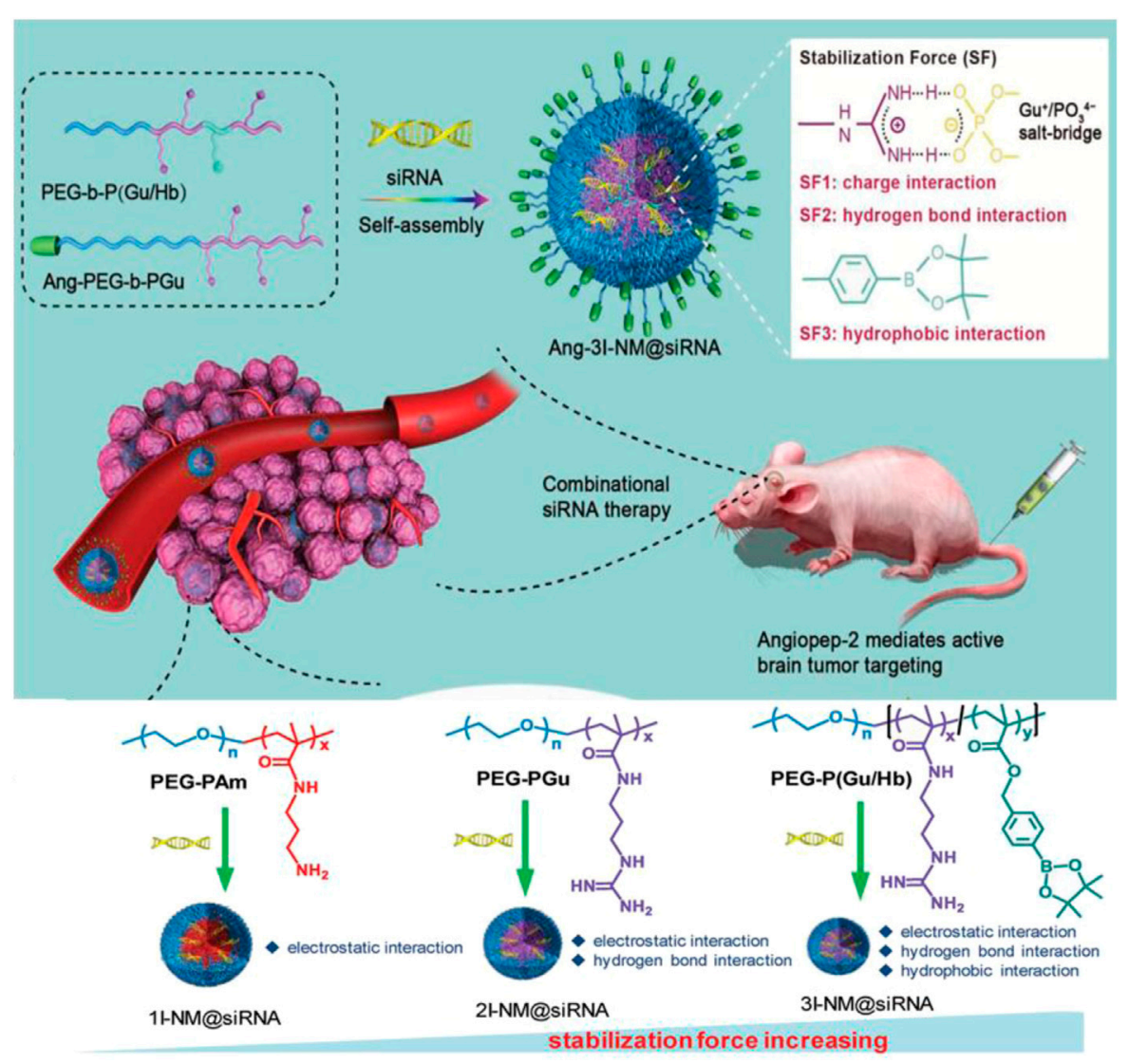

FIGURE 11 | Schematic illustration of 3I-NM@siRNA stabilized by electrostatic, hydrogen bond and hydrophobic interactions. The chemical structures of poly(ethylene glycol)-blockpoly (N-(3-aminopropyl methacrylamide) (PEG-Pam), poly(ethylene-glycol)-block-poly(N-(3-methacrylamidopropyl) guanidinium) (PEG-bPGu), and PEG-B-P (Gu/Hb) (Zheng et al., 2019). Copyright 2019, John Wiley and Sons.

\section{ARYLBORONIC ACID/ ESTER-CONTAINING POLYMERS}

Among the various functional groups of ROS-responsive reaction, arylboronic acid and ester are unique because they are highly selectively to oxidation by $\mathrm{H}_{2} \mathrm{O}_{2}$ and generate phenol and boronic acid as the oxidation products ( $\mathrm{Li}$ et al., 2017). This feature has enabled to explore ROS-responsive targeted drug delivery polymers and has also received increasing attention (Deng et al., 2016; Stubelius et al., 2019).

Arylboronic acid/ester-containing polymers exhibit distinctive structures from those mentioned previously. Arylboronic acid/ ester-containing structures rarely exist in the main backbone chain of a polymer, while polymers containing arylboronic acid/ ester functional groups in the side chain have been developed by stepwise polymerization (Cui et al., 2017) and ROP (Qiu et al., 2017) with arylboronic acid/ester pendant monomers. Arylboronic acid/ester exhibits structural advantages that allow, specifically, conjugation to polyhydroxy compounds having an ortho- or meta-diol structure (Xin et al., 2019; Jager et al., 2020). Kuang et al. synthesized nitrogen mustard prodrugs starting from 4-(bromomethyl) phenylboronic acid pinacol ester. They were pioneers in the field and discovered that anticancer prodrugs could be activated by ROS to release DNA cross-linking agents (Kuang et al., 2011 19278-19281). Xin et al. developed a ROS-responsive neuroprotective drug delivery carrier (SHpRBCNP) modified by a boronic ester group, stroke homing peptide (SHp), and a red blood cell (RBC). The SHp-RBCNP could prolong the systemic circulation of the neuroprotective drug (NR2B9C), enhance active targeting to the ischemic area in rat models of middle cerebral artery occlusion, and reduce ischemic brain damage ( $\mathrm{Lv}$ et al., 2018). The dual-responsive arylboronic ester polymers were also synthesized as $\mathrm{ROS} / \mathrm{pH}$ dual-responsive amphiphilic copolymers (Song et al., 2013). The design strategies of reactive arylboronic acid/ester nanodrugs have become increasingly sophisticated. Shi et al. reported a ROS-responsive polymer carrier (3I-NM@siRNA) constructed to carry small interfering RNA (siRNA) stabilized by electrostatic, hydrogen bond and hydrophobic interactions with the aim to improve siRNA circulation stability and delivery efficiency. The poly(ethylene glycol)-block-poly[(N-(3-methacrylamidopropyl) guanidinium-co-4-(4,4,5,5-tetramethyl-1,3,2-dioxaborolan-2-yl benzylacrylate) $](\mathrm{PEG}-\mathrm{B}-\mathrm{P}(\mathrm{Gu} / \mathrm{Hb}))$ was prepared as shown in Figure 11. $P E G-B-P(G u / H b)$ exhibits triple interactions, with the electrostatic and hydrogen bonding properties provided by the $\mathrm{Gu}^{+} / \mathrm{PO}_{3}{ }^{4-}$ bridge, and the arylboronic ester providing the 
hydrophobic interactions. Hydrophobic interactions were destroyed upon exposure concentrations of $\mathrm{H}_{2} \mathrm{O}_{2} \quad 100 \mu \mathrm{M}$; however, when given in the presence of the arylboronic ester group, the preparation could respond to ROS, and the by-product carboxyl groups could subsequently interfere with electrostatic and hydrogen bond interactions. This complicated process resulted in the effective release of the siRNA nanomedicine (Zheng et al., 2019). Shen et al. also synthesized poly[(2acryloyl)ethyl(p-boronic acid benzyl)diethylammonium bromide] (B-PDEAEA) for higher gene transfection efficiency. When B-PDEAEA is degraded by ROS, a negative charge reversal would cause the rapid release of DNA. In addition, boronate acid/ esters and their ultimate products are considered nontoxic to humans (Liu et al., 2016).

\section{OTHER POLYMER SYSTEMS}

\section{Aryl Oxalate-Containing Polymers}

Aryl oxalates may react with $\mathrm{H}_{2} \mathrm{O}_{2}$ to form 1,2-dioxetanediones, which can be rapidly converted into carbon dioxide $\left(\mathrm{CO}_{2}\right)$ and phenols. Thus, aryl oxalate ester bonds in polymerized nanoparticles may induce degradation and then release the payload when exposed to $\mathrm{H}_{2} \mathrm{O}_{2}$ to achieve intelligent delivery of drugs (Kim et al., 2017).

Aryl oxalates as functional groups generally have been introduced in the backbone chain of the polymer or in the side chain. Polymers containing oxalate in the main chain can be synthesized by stepwise polymerization, and polymers containing oxalate in the side chain can be synthesized via ROP from oxalate-containing norbornene or fragmentation chain transfer (RAFT) polymerization reactions using oxalatecontaining methacrylate. Aryl oxalates with negative groups are more beneficial to improve chemiluminescence than aliphatic oxalates. Polymers containing oxalate have been adopted to detect $\mathrm{H}_{2} \mathrm{O}_{2}$ using this property. Kang et al. synthesized a biodegradable p-hydroxybenzyl alcohol-incorporated copolyoxalate (HPOX) in a one-step condensation reaction of oxalyl chloride, 1,4-cyclohexanedimethanol, and p-hydroxybenzyl alcohol (HBA). HPOX degrades completely in the presence of $\mathrm{H}_{2} \mathrm{O}_{2}$, and the degradation products are cyclohexanedimethanol, $\mathrm{HBA}$, and $\mathrm{CO}_{2}$. Thus, HPOX nanoparticles effectively release $\mathrm{HBA}$, which in turn inhibits the production of nitric oxide (NO), thus revealing their ability as a targeted drug delivery system. HPOX has prospects for widespread applicability due to its biodegradable and biocompatible properties (Park et al., 2010; Lee D. et al., 2013). Wu et al. synthesized a PH/ROS dual-responsive triblock polymer (PRDSP) via $\mathrm{Cu}$ (I)-catalyzed azide-alkyne cycloaddition click polymerization to increase the sensitivity of peroxalate-based nanoparticles. PRDSP is characterized by a disulfide bond, triazole, and peroxalate ester structure in the backbone chain, which allows PRDSP to be cleaved by acid and $\mathrm{H}_{2} \mathrm{O}_{2}$ (Wu et al., 2015). DOX is quickly released from DOXloaded PRDSP nanoparticles in the presence of GSH $(10 \mathrm{mM})$ and $\mathrm{H}_{2} \mathrm{O}_{2}(10 \mathrm{mM})$, and thus, under acidic conditions, DOX release would be accelerated.

\section{Proline Oligomer}

The side chains of several amino acids in proteins are easily oxidized by ROS to produce carbonyl derivatives, mainly including proline, cysteine, methionine, tyrosine, histidine, and asparagine, and the chains that are the main backbone of proteins are fragmented to form carbonyl derivatives (Garrison, 1987; Stadtman and Levine, 2003; Lee et al., 2014). Proline is one of the most important amino acids that can undergo oxidation for degradation, as it can produce tertiary amide bonds with relatively stronger oxidation properties. Among all ROS-responsive functional groups, the proline oligomer exhibits a relatively slower degradation rate; thus, the proline oligomer was often used for sustained drug release preparations (oxidation-responsive polymeric scaffolds) on the basis of this oxidation-induced cleavage property (Ye et al., 2019). Sung et al. prepared porous polymeric scaffolds via terpolymer composed of PEG, poly $(\varepsilon-$ caprolactone) (PCL), poly(carboxyl- $\varepsilon$-caprolactone) (cPCL), and proline oligomers as cross-linkers. The properties of polymeric scaffolds could be tuned by the ratios of the PEG, PCL, and CPCL chain segments. The scaffolds selected $4 \%$ PEG, $86 \%$ PCL, and 10\% cPCL could slow degradation for over 20 weeks in conditions containing $\mathrm{H}_{2} \mathrm{O}_{2}$ (Yu et al., 2011).

\section{Ferrocene-Containing Polymers}

Ferrocene is a prototypical metallocene, a type of organometallic chemical compound, consisting of two cyclopentadienyl rings bound on opposite sides of a central metal atom. The rapid interest in organometallic chemistry is attributed to the excitement arising from the discovery of ferrocene and its many analogs due to its reversible redox activity, stability, and ease of synthesis. Hydrophobic ferrocene groups are rapidly quickly oxidized into hydrophilic ferricinium; this phase transition characteristic has been employed to trigger ROSresponsive drug release. For example, $\mathrm{Xu}$ et al. synthesized ferrocene-containing amphiphilic block polymers (PACMO-bPAEFC) by atom transfer radical polymerization (ATRP), with poly(N-acryloylmorpholine) (PACMO) as the hydrophilic blocks and poly(2-acryloyloxyethyl ferrocenecarboxylate) (PAEFC) as the hydrophobic blocks. PACMO-b-PAEFC micelles showed a high PTX encapsulation efficiency of $61.4 \%$ and swelled to release the PTX in the presence of ROS. The PTX release rate was mediated by the type and concentration of oxidants. In addition, PACMO-b-PAEFC exhibited low toxicity even at high concentrations of approximately $500 \mu \mathrm{g} \mathrm{ml}^{-1}$ (Xu F. et al., 2017).

\section{CONCLUSION AND FUTURE CHALLENGES}

In the past two decades, many novel ROS-responsive polymers for drug delivery systems have been described, and their structure and function are constantly being improved. ROS-responsive polymers for drug delivery systems have been recognized as a valuable strategy to control drug delivery with low toxicity. Due to the differences in the characteristics of the tumor microenvironment compared to normal cells, ROS-responsive polymer delivery systems meet the theoretical requirements of 
targeted therapy. With the addition of different reducing structures or functional groups, ROS-responsive polymer systems are moving in the direction of lower toxicity and higher efficiency.

Nonetheless, biocompatible and biodegradable features of different polymers must be improved. If drug delivery carriers are not metabolized or degraded, a large number of carriers will eventually accumulate in normal tissue and inevitably result in damage to normal cell functions, with the possibility of inducing unpredictable systemic toxicity and side effects. Thus, degradable polymers in drug delivery applications had become a prominent research interest due to their biocompatible and degradable properties (Kamaly et al., 2016). The degradable polymers break down inside the body to produce nontoxic natural byproducts such as water and carbon dioxide, which are easily eliminated.

Meanwhile, it is urgent to improve the delivery efficiency of polymer carriers. It should be noted that although the concentration of ROS in tumor cells is higher than that in normal cells, ROS levels are still insufficient to fully activate the currently available ROS-sensitive carriers. Thus, delivery systems that respond to multiple stimuli have become a popular strategy of current research because they are safer and achieve superior targeting than delivery systems directed at one stimulus (Roy et al., 2010; Zhang Q. et al., 2017; Cheng et al., 2019; Ma B. X. et al., 2020). However, combining multiple functions into one delivery system remains a challenge. A second excellent approach involves amplification of the intracellular oxidative stress level to improve the response toward polymer nanocarriers.

\section{REFERENCES}

Allen, B. L., Johnson, J. D., and Walker, J. P. (2011). Encapsulation and enzymemediated release of molecular cargo in polysulfide nanoparticles. ACS Nano 5, 5263-5272. doi:10.1021/nn201477y

Barnham, K. J., Masters, C. L., and Bush, A. I. (2004). Neurodegenerative diseases and oxidative stress. Nat. Rev. Drug Discov. 3, 205-214. doi:10.1038/nrd1330

Cao, W., Gu, Y. W., Meineck, M., Li, T. Y., and P Xu, H. (2014). Tellurium-containing polymer micelles: competitive-ligand-regulated coordination responsive systems. J. Am. Chem. Soc. 136 (13), 5132-5137. doi:10.1021/ja500939m

Cao, W., Gu, Y. W., Li, T. Y., and Xu, H. P (2015). Ultra-sensitive ROS-responsive tellurium-containing polymers. Chem. Commun. 51, 7069-7071. doi:10.1039/ c5cc01779c

Chen, X., Wang, F., Hyun, J. Y., Wei, T., Qiang, J., Ren, X., et al. (2016). Recent progress in the development of fluorescent, luminescent and colorimetric probes for detection of reactive oxygen and nitrogen species. Chem. Soc. Rev. 45, 2976-3016. doi:10.1039/c6cs00192k

Chen, Y., Xia, R., Huang, Y., Zhao, W., Li, J., Zhang, X., et al. (2016). An immunostimulatory dual-functional nanocarrier that improves cancer immunochemotherapy. Nat. Commun. 7, 13443. doi:10.1038/ ncomms 13443

Cheng, R., Feng, F., Meng, F., Deng, C., Feijen, J., and Zhong, Z. (2011). Glutathione-responsive nano-vehicles as a promising platform for targeted intracellular drug and gene delivery. J. Controlled Release 152, 2-12. doi:10. 1016/j.jconrel.2011.01.030

Cheng, D. B., H Zhang, X., Gao, Y. J., Ji, L., Hou, D. Y., Wang, Z. Q., et al. (2019). Endogenous reactive oxygen species-triggered morphology transformation for enhanced cooperative interaction with mitochondria. J. Am. Chem. Soc. 141 (18), 7235-7239. doi:10.1021/jacs.8b07727
Intracellular oxidative stress could be selectively amplified by the introduction of ROS production agents or via the inhibition of intracellular antioxidant systems. (Li J. et al., 2020; Zhang et al., 2020) Furthermore, more functional polymer carriers can be engineered by introducing specific functional building blocks and by applying a design rationale favoring ROS-responsive polymers for drug delivery systems, which not only serve as carriers to deliver active drugs but also exert synergistic effects with the drug and greatly improve the therapeutic outcome of the drug (Ma S. et al., 2020).

Although there are many challenges to overcome (El-Sawy et al., 2018; Rao et al., 2018; Kwon et al., 2019), we expect more innovative ideas and original ideas in this field. Through systematic and in-depth research and careful scientific evaluation, ROS-responsive polymers for drug delivery are expected to provide new opportunities and wider application for the specific treatment of tumors and other diseases.

\section{AUTHOR CONTRIBUTIONS}

All authors listed have made a substantial, direct, and intellectual contribution to the work.

\section{FUNDING}

This work was supported by Major Special Science and Technology Project of Jilin Province, China (No. 20200501002GX).

Chiang, Y.-T., Yen, Y.-W., and Lo, C.-L. (2015). Reactive oxygen species and glutathione dual redox-responsive micelles for selective cytotoxicity of cancer. Biomaterials 61, 150. doi:10.1016/j.biomaterials.2015.05.007

Cui, Y., Zhang, M., Du, F. S., and Li, Z. C. (2017). Facile synthesis of $\mathrm{H}_{2} \mathrm{O}_{2}$-cleavable poly(ester-amide)s by passerini multicomponent polymerization. ACS Macro Lett. 6 (1), 11-15. doi:10.1021/acsmacrolett.6b00833

D'Autreaux, B., and Toledano, M. B. (2007). ROS as signalling molecules: mechanisms that generate specificity in ROS homeostasis. Nat. Rev. Mol. Cel Biol. 8, 813-824. doi:10.1038/nrm2256

De Palma, M., Biziato, D., and Petrova, T. V. (2017). Microenvironmental regulation of tumour angiogenesis. Nat. Rev. Cancer 17, 457-474. doi:10. 1038/nrc.2017.51

Deng, Z. Y., Qian, Y. F., Yu, Y. Q., Liu, G. H., Hu, J. M., Zhang, G. Y., et al. (2016). Engineering intracellular delivery nanocarriers and nanoreactors from oxidation-responsive polymersomes via synchronized bilayer cross-linking and permeabilizing inside live cells. J. Am. Chem. Soc. 138 (33), 10452-10466. doi:10.1021/jacs.6b04115

Deng, Z., Hu, J., and Liu, S. (2017). Reactive oxygen, nitrogen, and sulfur species (RONSS)-Responsive polymersomes for triggered drug release. Macromol. Rapid Commun. 38, 1600685-1600695. doi:10.1002/marc.201600685

Dharmaraja, A. T. (2017). Role of reactive oxygen species (ROS) in therapeutics and drug resistance in cancer and bacteria. J. Med. Chem. 60, 3221-3240. doi:10. 1021/acs.jmedchem.6b01243

Du, Y. W., He, W., Xia, Q., Zhou, W. Y., Yao, C., and Li, X. S. (2019). Thioether phosphatidylcholine liposomes: a novel ROS-responsive platform for drug delivery. ACS Appl. Mater. Inter. 11, 37411-37420. doi:10.1021/acsami. $9 \mathrm{~b} 08901$

Eleftheriadou, D., Kesidou, D., Moura, F., Felli, E., and Song, W. (2020). Redoxresponsive nanobiomaterials-based therapeutics for neurodegenerative diseases. Small 16, 1907308. doi:10.1002/smll.201907308 
El-Sawy, H. S., Al-Abd, A. M., Ahmed, T. A., El-Say, K. M., and Torchilin, V. P. (2018). Stimuli-responsive nano-architecture drug-delivery systems to solid tumor micromilieu: past, present, and future perspectives. ACS Nano 12, 10636-10664. doi:10.1021/acsnano.8b06104

Fang, R., Xu, H., Cao, W., Yang, L., and Zhang, X. (2015). Reactive oxygen species (ROS)-responsive tellurium-containing hyperbranched polymer. Polym. Chem. 6, 2817-2821. doi:10.1039/c5py00050e

Fraisl, P., Aragonés, J., and Carmeliet, P. (2009). Inhibition of oxygen sensors as a therapeutic strategy for ischaemic and inflammatory disease. Nat. Rev. Drug Discov. 8, 139-152. doi:10.1038/nrd2761

Fu, Y., Chen, J., Xu, H., Van Oosterwijck, C., Zhang, X., Dehaen, W., et al. (2012). Fully- branched hyperbranched polymers with a diselenide core as glutathione peroxidase mimics. Macromol. Rapid Commun. 33, 798-804. doi:10.1002/marc. 201100860

Fu, X., Ma, Y., Shen, Y., Fu, W., and Li, Z. (2014). Oxidation-responsive OEGylated poly-l-cysteine and solution properties studies. Biomacromolecul. 15, 1055. doi:10.1021/bm5000554

Gao, S. Q., Li, T. Y., Guo, Y., Sun, C., Banruo, X., and P Xu, H. (2020). Seleniumcontaining nanoparticles combine the NK cells mediated immunotherapy with radiotherapy and chemotherapy. Adv. Mater. 32, 1907568. doi:10.1002/adma. 201907568

Garrison, W. M. (1987). Reaction mechanisms in the radiolysis of peptides, polypeptides, and proteinst. Chem. Rev. 87, 381-398. doi:10.1021/cr00078a006

Gligorovski, S., Strekowski, R., Barbati, S., and Vione, D. (2015). Environmental implications of hydroxyl radicals (OH). Chem. Rev. 115, 13051-13092. doi:10. $1021 /$ cr500310b

Han, P., Ma, N., Ren, H., Xu, H., Li, Z., Wang, Z., et al. (2010). Oxidationresponsive micelles based on a selenium-containing polymeric superamphiphile. Langmuir 26, 14414-14418. doi:10.1021/la102837a

Han, P., Li, S., Cao, W., Li, Y., Sun, Z., Wang, Z., et al. (2013). Red light responsive diselenide-containing block copolymer micelles. J. Mater. Chem. B. 1, 740-743. doi:10.1039/c2tb00186a

Hayyan, M., Hashim, M. A., and AlNashef, I. M. (2016). Superoxide ion: generation and chemical implications. Chem. Rev. 116, 3029-3085. doi:10.1021/acs. chemrev.5b00407

Hu, P., and Tirelli, N. (2012). Scavenging ROS: superoxide dismutase/catalase mimetics by the use of an oxidation-sensitive nanocarrier/enzyme conjugate. Bioconjug. Chem. 23 (3), 438-449. doi:10.1021/bc200449k

Hu, B., Lian, Z. W., Zhou, Z. F., Shi, L. Q., and Yu, Z. L. (2020). Reactive oxygen species-responsive adaptable self-assembly of peptides toward advanced biomaterials. ACS Appl. Bio Mater. 3, 5529-5551. doi:10.1021/acsabm.0c00758

Jager, E., Sincari, V., Albuquerque, L. J. C., Jäger, A., Humajova, J., Jan, K., et al. (2020). Reactive oxygen species (ROS)-Responsive polymersomes with sitespecific chemotherapeutic delivery into tumors via spacer design chemistry. Biomacromolecules 21, 1437-1449. doi:10.1021/acs.biomac.9b01748

Kamaly, N., Yameen, B., Wu, J., and Farokhzad, O. C. (2016). Degradable controlled-release polymers and polymeric nanoparticles: mechanisms of controlling drug release. Chem. Rev. 116, 2602-2663. doi:10.1021/acs. chemrev.5b00346

Kim, G.-W., Kang, C., Oh, Y.-B., Ko, M.-H., Seo, J.-H., and Lee, D. (2017). Ultrasonographic imaging and anti-inflammatory therapy of muscle and tendon injuries using polymer nanoparticles. Theranostics 7 (9), 2463. doi:10.7150/thno.18922

Kuang, Y., Baakrishnan, K., Gandhi, V., and Peng, X. (2011). Hydrogen peroxide inducible DNA cross-linking agents: targeted anticancer prodrugs. J. Am. Chem. Soc. 133 (48), 19278-19281. doi:10.1021/ja2073824

Kwon, S., Ko, H., You, D. G., Kataoka, K., and Park, J. H. (2019). Nanomedicines for reactive oxygen species mediated approach: an emerging paradigm for cancer treatment. Acc. Chem. Res. 52 (7), 1771-1782. doi:10.1021/acs.accounts. $9 \mathrm{~b} 00136$

Lee, D., Bae, S., Ke, Q., Lee, J., Song, B., Karumanchi, S. A., et al. (2013). Hydrogen peroxide-responsive copolyoxalate nanoparticles for detection and therapy of ischemia-reperfusion injury. J. Controlled Release 172, 1102. doi:10.1016/j. jconrel.2013.09.020

Lee, S. H., Gupta, M. K., Bang, J. B., Bae, H., and Sung, H.-J. (2013). Current progress in reactive oxygen species (ROS)-Responsive materials for biomedical applications. Adv. Healthc. Mater. 2, 908-915. doi:10.1002/adhm.201200423
Lee, S. H., Boire, T. C., Lee, J. B., Gupta, M. K., Zachman, A. L., Rath, R., et al. (2014). ROS-cleavable proline oligomer crosslinking of polycaprolactone for pro-angiogenic host response. J. Mater. Chem. B. 2 (41), 7109-7113. doi:10. 1039/c4tb01094a

Li, T. Y., Li, F., Xiang, W. T., Yi, Y., Chen, Y. Y., Cheng, L., et al. (2016). Seleniumcontaining amphiphiles reduced and stabilized gold nanoparticles: Kill cancer cells via reactive oxygen species. ACS. Appl. Mater. Inter. 8, 22106-22112. doi:10.1021/acsami.6b08282

Li, C., Pan, R., Li, P., Guan, Q., and Ao, J. (2017). Hydrogen peroxide-responsive nanoprobe assists circulating tumor cell identification and colorectal cancer diagnosis. Anal. Chem. 89 (11), 5966-5975. doi:10.1021/acs.analchem.7b00497

Li, J., Wei, Y. J., Yang, X. L., Wu, W. X., Zhang, M. Q., Li, M. Y., et al. (2020). Rational construction of a mitochondrial targeting, fluorescent self-reporting drug-delivery platform for combined enhancement of endogenous ROS responsiveness. ACS Appl. Mater. Inter. 12, 32432-32445. doi:10.1021/ acsami.0c08336

Li, T. Y., Pan, S. J., Zhuang, H., Gao, S. Q., and Xu, H. P. (2020). Seleniumcontaining carrier-free assemblies with aggregation-induced emission property combine cancer radiotherapy with chemotherapy. ACS Appl. Bio Mater. 3 (2), 1283-1292. doi:10.1021/acsabm.9b01172

Liu, J., Pang, Y., Chen, J., Huang, P., Huang, W., Zhu, X., et al. (2012). Hyperbranched polydiselenide as a self assembling broad spectrum anticancer agent. Biomaterials 33 (31). 7765-7774. doi:10.1016/j. biomaterials.2012.07.003

Liu, X., Xiang, J. J., Zhu, D. C., Jiang, L. M., Zhou, Z. X., Tang, J. B., et al. (2016). Fusogenic reactive oxygen species triggered charge-reversal vector for effective gene delivery. Adv. Mater. 28 (9), 1743-1752. doi:10.1002/adma.201504288

Liu, H., Wang, R., Wei, J., Cheng, C., Zheng, Y., Pan, Y., et al. (2018). Conformation-directed micelle-to-vesicle transition of cholesterol-decorated polypeptide triggered by oxidation. J. Am. Chem. Soc. 140 (21), 6604-6610. doi:10.1021/jacs.8b01873

Liu, T.-I., Yang, Y.-C., Chiang, W.-H., Hung, C.-K., Tsai, Y.-C., Chiang, C.-S., et al. (2018). Radiotherapy-controllable chemotherapy from reactive oxygen speciesresponsive polymeric nanoparticles for effective local dual modality treatment of malignant tumors. Biomacromolecules 19 (9), 3825-3839. doi:10.1021/acs. biomac.8b00942

Liu, Y., Liu, Y. Q., Zang, J., Li, Y., and Dong, H. Q. (2020). Design strategies and applications of ROS-responsive phenylborate ester-based nanomedicine. ACS Biomater. Sci. Eng. 6 (12), 6510-6527. doi:10.1021/acsbiomaterials.0c01190

Lou, Z., Li, P., and Han, K. (2015). Redox-responsive fluorescent probes with different design strategies. Acc. Chem. Res. 48, 1358. doi:10.1021/acs.accounts. 5 b00009

Lu, Y., Aimetti, A., Langer, R., and Gu, Z. (2017). Bioresponsive materials. Nat. Rev. Mater. 2, 16075. doi:10.1038/natrevmats.2016.75

Luo, C.-Q., Zhou, Y.-X., Zhou, T.-J., Xing, L., Cui, P.-F., Sun, M., et al. (2018). Reactive oxygen species-responsive nanoprodrug with quinone methidesmediated GSH depletion for improved chlorambucil breast cancers therapy. J. Control Release 274, 56-68. doi:10.1016/j.jconrel.2018.01.034

Lv, W., Xu, J. P., Wang, X. Q., Li, X., Xu, Q. W., and Xin, H. (2018). Bioengineered boronic ester modified dextran polymer nanoparticles as reactive oxygen species responsive nanocarrier for ischemic stroke treatment. ACS Nano 12, 5417-5426. doi:10.1021/acsnano.8b00477

Ma, N., Li, Y., Ren, H. F., Xu, H. P., Li, Z. B., and Zhang, X. (2010a). Seleniumcontaining block copolymers and their oxidation- responsive aggregates. Polym. Chem. 1 (10), 1609-1614. doi:10.1039/c0py00144a

Ma, N., Li, Y., Xu, H., Wang, Z., and Zhang, X. (2010b). Dual redox responsive assemblies formed from diselenide block copolymers. J. Am. Chem. Soc. 132, 442. doi:10.1021/ja908124g

Ma, N., Xu, H., An, L., Li, J., Sun, Z., and Zhang, X. (2011). Radiation-sensitive diselenide block copolymer micellar aggregates: toward the combination of radiotherapy and chemotherapy. Langmuir 27, 5874-5878. doi:10.1021/ la2009682

Ma, B. X., Xu, H., Zhuang, W. H., Wang, Y. A., Li., G.C., and Wang, Y. B. (2020). Reactive oxygen species responsive theranostic nanoplatform for two-photon aggregation-induced emission imaging and therapy of acute and chronic inflammation. ACS Nano 14, 5862-5873. doi:10.1021/acsnano. 0c01012 
Ma, S., Song, W. T., Xu, Y. D., Si, X. H., Lv, S. X., Zhang, Y., et al. (2020). Rationally designed polymer conjugate for tumor-specific amplification of oxidative stress and boosting antitumor immunity. Nano Lett. 20, 2514-2521. doi:10.1021/acs. nanolett.9b05265

Napoli, A., Valentini, M., Tirelli, N., Müller, M., and Hubbell, J. A. (2004). Oxidation-responsive polymeric vesicles. Nat. Mater 3, 183-189. doi:10. 1038/nmat 1081

Natalia, O., Francesca, P., Jason, T., Chiara, A., Benedictis, D., Grabrucker, A. M., et al. (2019). ROS-responsive "smart" polymeric conjugate: synthesis, characterization and proof-of-concept study. Int. J. Pharmaceutics 570, 118655. doi:10.1016/j.ijpharm.2019.118655

Nosaka, Y., and Nosaka, A. Y. (2017). Generation and detection of reactive oxygen species in photocatalysis. Chem. Rev. 117, 11302-11336. doi:10.1021/acs. chemrev.7b00161

Owen, S., Fenton, N. K., Padmini, S. O., Michael, J. P., and Langer, M. R. (2018). Advances in biomaterials for drug delivery. Adv. Mater. 30, 1705328. doi:10. 1002/adma.201705328

Park, H., Kim, S., Kim, S., Song, Y., Seung, K., Hong, D., et al. (2010). Antioxidant and anti-inflammatory activities of hydroxybenzyl alcohol releasing biodegradable polyoxalate nanoparticles. Biomacromolecul. 11, 2103-2108. doi:10.1021/bm100474w

Qiu, F. Y., Zhang, M., Du, F. S., and Li, Z. C. (2017). Oxidation degradable aliphatic polycarbonates with pendent phenylboronic ester. Macromolecules 50 (1), 23-34. doi:10.1021/acs.macromol.6b01883

Rao, N. V., Ko, H., Lee, J., and Park, J. H. (2018). Recent progress and advances in stimuli-responsive polymers for cancer therapy. Front. Bioeng. Biotechnol. 13, 110. doi:10.3389/fbioe.2018.00110

Ren, H., Wu, Y., Ma, N., Xu, H., and Zhang, X. (2012). Side-chain seleniumcontaining amphiphilic block copolymers: redox-controlled self-assembly and disassembly. Soft Matter 8, 1460-1466. doi:10.1039/c1sm06673k

Ren, H., Wu, Y., Li, Y., Cao, W., Sun, Z., Xu, H., et al. (2013). Visible- light-induced disruption of diselenide-containing layer-bylayer films: toward combination of chemotherapy and photodynamic therapy. Small 9 (23), 3981-3986. doi:10. 1002/smll.201300628

Roy, D., Cambre, J. N., and Sumerlin, B. S. (2010). Future perspectives and recent advances in stimuli-responsive materials. Prog. Polym. Sci. 35, 278-301. doi:10. 1016/j.progpolymsci.2009.10.008

Saravanakumar, G., Kim, J., and Kim, W. J. (2017). Reactive-oxygen-speciesresponsive drug delivery systems: promises and challenges. Adv. Sci. 4, 1600124. doi:10.1002/advs.201600124

Schumacker, P. T. (2015). Reactive oxygen species in cancer: a dance with the devil. Cancer Cell 27 (2), 156-157. doi:10.1016/j.ccell.2015.01.007

Shim, M. S., and Xia, Y. (2013). A reactive oxygen species (ROS)-Responsive polymer for safe, efficient, and targeted gene delivery in cancer cells. Angew. Chem. Int. Ed. 52, 6926-6929. doi:10.1002/anie.201209633

Song, C-C., Ji, R., Du, F. S., and Li, Z. C. (2013). Oxidation-responsive poly(amino ester)s containing arylboronic ester and self-immolative motif: synthesis and degradation study. Macromolecules 46, 8416-8425. doi:10.1021/ma401656t

Song, C.-C., Du, F.-S., and Li, Z.-C. (2014). Oxidation-responsive polymers for biomedical applications. J. Mater. Chem. B 2, 3413-3426. doi:10.1039/ c3tb21725f

Stadtman, E., and Levine, R. (2003). Free radical-mediated oxidation of free amino acids and amino acid residues in proteins. Amino Acids 25, 207-218. doi:10. 1007/s00726-003-0011-2

Stubelius, A., Lee, S., and Almutairi, A. (2019). The chemistry of boronic acids in nanomaterials for drug delivery. Acc. Chem. Res. 52 (11), 3108-3119. doi:10. 1021/acs.accounts.9b00292

Su, M. F., Xiao, S. T., Shu, M., Lu, Y., Zeng, Q., Xie, J. H., et al. (2020). Enzymatic multifunctional biodegradable polymers for $\mathrm{pH}$-and ROS-responsive anticancer drug delivery. Colloids Surf. B Biointerfaces. 193, 111067. doi:10. 1016/j.colsurfb.2020.111067

Sun, T., Jin, Y., Qi, R., Peng, S., and Fan, B. (2013a). Oxidation responsive monocleavable amphiphilic di-block polymer micelles labeled with a single diselenide. Polym. Chem. 4 (14), 4017-4023. doi:10.1039/c3py00406f

Sun, T., Jin, Y., Qi, R., Peng, S., and Fan, B. (2013b). Post-assembly of oxidation- responsive amphiphilic triblock polymer containing a single diselenide. Macromol. Chem. Phys. 214 (24), 2875-2881. doi:10.1002/macp. 201300579
Sun, C., Ji, S., Li, F., and $\mathrm{Xu}, \mathrm{H}$. (2017). Diselenide-containing hyperbranched polymer with light-induced cytotoxicity. ACS.Appl.Mater.Interfaces 9 (15), 12924-12929. doi:10.1021/acsami.7b02367

Sun, C.-Y., Cao, Z., Zhang, X.-J., Sun, R., Yu, C.-S., and Yang, X. (2018). Cascadeamplifying synergistic effects of chemo-photodynamic therapy using ROSresponsive polymeric nanocarriers. Theranostics 8, 2939-2953. doi:10.7150/ thno. 24015

Sun, B., Luo, C., and Zhang, X. (2019). Probing the impact of sulfur/selenium/ carbon linkages on prodrug nanoassemblies for cancer therapy. Nat. Commun. 10, 3211. doi:10.1038/s41467-019-11193-x

Tan, X., Yu, Y., Liu, K., Xu, H., Liu, D., Wang, Z., et al. (2012). Single-molecule force spectroscopy of selenium-containing amphiphilic block copolymer: toward disassembling the polymer micelles. Langmuir 28, 9601. doi:10.1021/ la301703t

Trachootham, D., Alexandre, J., and Huang, P. (2009). Targeting cancer cells by ROS-mediated mechanisms: a radical therapeutic approach?. Nat. Rev. Drug Discov. 8, 579-591. doi:10.1038/nrd2803

Wang, J., Pei, Q., Xia, R., Liu, S., Hu, X., Xie, Z. G., et al. (2011). Comparison of redox responsiveness and antitumor capability of paclitaxel dimeric nanoparticles with different linkers. Chem. Mater. Article ASAP 24, 10719-10727. doi:10.1021/acs.chemmater.0c04080

Wang, J., Sun, X., Mao, W., Sun, W., Tang, J., Sui, M., et al. (2013). Tumor redox heterogeneity-responsive prodrug nanocapsules for cancer chemotherapy. Adv. Mater. 25. 3670-3676. doi:10.1002/adma.201300929

Wang, L., Fan, F. Q., Cao, W., and Xu, H. (2015). Ultrasensitive ROS-responsive coassemblies of tellurium-containing molecules and phospholipids ACS. Appl. Mater. Inter. 7, 16054-16060. doi:10.1021/acsami.5b04419

Wang, L., Wang, W., Cao, W., and Xu, H. (2017). Multi-hierarchical responsive polymers: stepwise oxidation of a selenium-and tellurium-containing block copolymer with sensitivity to both chemical and electrochemical stimuli. Polym. Chem. 8, 4520-4527. doi:10.1039/c7py00971b

Wang, G. C., Huang, P., Qi, M. W., Li, C. L., Fan, W., Zhou, Y. F., et al. (2019). Facile synthesis of a $\mathrm{H}_{2} \mathrm{O}_{2}$-responsive alternating copolymer bearing thioether side groups for drug delivery and controlled release. ACS Omega 4, 17600-17606. doi:10.1021/acsomega.9b02923

Wang, J. H., Li, D.-d., Tao, W., Lu, Y., Yang, X. Z., and Wang, J. (2019). Synthesis of an oxidation-sensitive polyphosphoester bearing thioether group for triggered drug release. Biomacromolecul. 20, 1740-1747. doi:10.1021/acs.biomac. $9 \mathrm{~b} 00101$

Wang, H., Chai, L., Xie, Z., and Zhang, H. (2020). Recent advance of tellurium for biomedical applications. Chem. Res. Chin. Univ. 36, 551-559. doi:10.1007/ s40242-020-0193-0

Wei, C., Xu, Y., Yan, B. K., Hou, J. Q., Du, Z. Z., and Lang, M. D. (2018). Welldefined selenium-containing aliphatic polycarbonates via lipase-catalyzed ringopening polymerization of selenic macrocyclic carbonate monomer. ACS Macro Lett. 7 (3), 336-340. doi:10.1021/acsmacrolett.8b00039

Wilson, D. S., Dalmasso, G., Wang, L., Sitaraman, S. V., Merlin, D., and Murthy, N. (2010). Orally delivered thioketal nanoparticles loaded with TNF-alpha-siRNA target inflammation and inhibit gene expression in the intestines. Nat. Mater. 9, 923-928. doi:10.1038/nmat2859

Wu, Y., Zhou, D., Qi, Y., Xie, Z., Chen, X., Jing, X., et al. (2015). Novel multisensitive pseudo-poly (amino acid) for effective intracellular drug delivery. RSC $A d v .5,31972-31983$. doi:10.1039/c5ra03423j

Sun, C., Tan, Y. Z., and Xu, H. (2020). From selenite to diselenide-containing drug delivery systems. ACS Mater. Lett. 2 (9), 1173-1177. doi:10.1021/ acsmaterialslett.0c00272

Xia, J. H., Li, F., Ji, S. B., and Xu, H. P. (2017). Selenium-functionalized graphene oxide that can modulate the balance of reactive oxygen species. ACS Appl. Mater. Inter. 9, 21413-21421. doi:10.1021/acsami.7b05951

Xia, J., Li, T. Y., Lu, C. J., and Xu, H. (2018). Selenium-containing polymers: perspectives toward diverse applications in both adaptive and biomedical materials. Macromolecul. 51, 7435-7455. doi:10.1021/acs.macromol.8b01597

Xiao, C., Ding, J., Ma, L., Yang, C., Zhuang, X., and Chen, X. (2015). Synthesis of thermal and oxidation dual responsive polymers for reactive oxygen species (ROS)-triggered drug release. Polym. Chem. 6, 738-747. doi:10.1039/ c4py01156b

Xin, X. F., Lin, F., Wang, Q. Y., Yin, L. F., and Mahato, R. I. (2019). ROS-responsive polymeric micelles for triggered simultaneous delivery of PLK1 inhibitor/miR- 
34a and effective synergistic therapy in pancreatic cancer. ACS Appl. Mater. Inter. 11, 14647-14659. doi:10.1021/acsami.9b02756

Xu, H., Gao, J., Wang, Y., Wang, Z., Smet, M., Dehaen, W., et al. (2006). Hyperbranched polyselenides as glutathione peroxidase mimics. Chem. Commun. 7, 796-798. doi:10.1039/b514701h

Xu, Q., He, C., Xiao, C., and Chen, X. (2016). Reactive oxygen species (ROS) responsive polymers for biomedical applications. Macromol. Biosci. 16, 635-646. doi:10.1002/mabi.201500440

Xu, F., Li, H., Luo, Y. L., and Tang, W. (2017). Redox-responsive self- assembly micelles from poly(N-Acryloylmorpholine-block-2-Acryloyloxyethyl ferrocenecarboxylate) amphiphilic block copolymers as drug release carriers. ACS Appl. Mater. Inter. 9 (6), 5181-5192. doi:10.1021/acsami.6b16017

Xu, X., Saw, P. E., Tao, W., Li, Y., Ji, X., Bhasin, S., et al. (2017). ROS-responsive polyprodrug nanoparticles for triggered drug delivery and effective cancer therapy. Adv. Mater. 29, 1700141. doi:10.1002/adma.201700141

Xu, L., Zhao, M. Y., Zhang, H., Gao, W. X., Guo, Z. Y., Zhang, X. Q., et al. (2018a). Cinnamaldehyde-based poly(ester-thioacetal) to generate reactive oxygen species for fabricating reactive oxygen species- responsive nanoparticles. Biomacromolecul. 19, 4658-4667. doi:10.1021/acs.biomac.8b01423

Xu, L., Yang, Y., Zhao, M., Gao, W., Zhang, H., Li, S., et al. (2018b). A reactive oxygen species-responsive prodrug micelle with efficient cellular uptake and excellent bioavailability. J. Mater. Chem. B 6, 1076-1084. doi:10.1039/ c7tb02479g

Xu, L., Zhao, M. Y., Gao, W. X., Yang, Y., Zhang, J. F., Pu, Y., et al. (2019). Polymeric nanoparticles responsive to intracellular ROS for anticancer drug delivery. Colloids Surf. B: Biointerfaces 181, 252-260. doi:10.1016/j.colsurfb.2019.05.064

Xu, H., Cao, W., and Zhang, X. (2013). Selenium-containing polymers promising biomaterials for controlled release and enzyme mimics. Acc. Chem. Res. 46, 1647-1658. doi:10.1021/ar4000339

Yang, B., Chen, Y., and Shi, J. (2019). Reactive oxygen species (ROS)-Based nanomedicine. Chem. Rev. 119, 4881-4985. doi:10.1021/acs.chemrev.8b00626

Yang, Y., Sun, B., Zuo, S., Li, X., Zhou, S., Li, L., et al. (2020). Trisulfide bond-mediated doxorubicin dimeric prodrug nanoassemblies with high drug loading, high self-assembly stability, and high tumor selectivity. Sci. Adv. 6, eabc1725. doi:10.1126/sciadv.abc1725

Ye, H., Zhou, Y., Liu, X., Chen, Y., Duan, S., Zhu, R., et al. (2019). Recent advances on reactive oxygen species-responsive delivery and diagnosis system. Biomacromolecul. 20 (7), 2441-2463. doi:10.1021/acs.biomac.9b00628

Yin, W., Ke, W. D., Lu, N., Wang, Y. H., Wang, Y., Pan, Y., et al. (2020). Glutathione and reactive oxygen species dual-responsive block copolymer prodrugs for boosting tumor site-specific drug release and enhanced antitumor efficacy. Biomacromolecul. 21, 921-929. doi:10.1021/acs.biomac. $9 \mathrm{~b} 01578$

Yu, S. S., Koblin, R. L., Zachman, A. L., Perrien, D. S., Hofmeister, L. H., Giorgio, T. D., et al. (2011). Physiologically relevant oxidative degradation of oligo(proline) cross-linked polymeric scaffolds. Biomacromolecul. 12 (12). 4357-4366. doi:10. 1021/bm201328k

Zhang, Q., Shen, C., Zhao, N., and Xu, F. J. (2017). Redox-responsive and drugembedded silica nanoparticles with unique self-destruction features for efficient gene/drug codelivery. Adv. Funct. Mater. 27, 1606229. doi:10.1002/adfm. 201606229

Zhang, Y., Guo, Q., An, S., Lu, Y., Li, J., He, X., et al. (2017). ROS-switchable polymeric nanoplatform with stimuli-responsive release for active targeted drug delivery to breast cancer. ACS Appl. Mater. Inter. 9, 12227-12240. doi:10. 1021/acsami.6b16815

Zhang, Y. X., Zhou, J., Ma, S. G., He, Y. Y., Yang, J., and Gu, Z. W. (2019). Reactive oxygen species (ROS)-Degradable polymeric nanoplatform for hypoxiatargeted gene delivery: unpacking DNA and reducing toxicity. Biomacromolecul. 20, 1899-1913. doi:10.1021/acs.biomac.9b00054

Zhang, X., Li, G., Liu, Z. T., Liu, Z., and Jiang, J. Q. (2020). Iminoboronate backbone-based hyperbranched polymeric micelles with fenton-like enhanced ROS response. Macromol. Chem. Phys. 221, 2000022. doi:10.1002/macp. 202000022

Zheng, M., Liu, Y. Y., Wang, Y. B., Zhang, D. Y., Zou, Yan., Ruan, W., et al. (2019). ROS-responsive polymeric siRNA nanomedicine stabilized by triple interactions for the robust glioblastoma combinational RNAi therapy. Adv. Mater. 31, 1903277. doi:10.1002/adma.201903277

Zhou, W. Q., Wang, L., Li, F., Zhang, W., Huang, W., Huo, F., et al. (2017). Selenium-containing Polymer@Metal-Organic frameworks nanocomposites as an efficient multiresponsive drug delivery system. Adv. Funct. Mater. 27, 1605465. doi:10.1002/adfm.201605465

Conflict of Interest: The authors declare that the research was conducted in the absence of any commercial or financial relationships that could be construed as a potential conflict of interest.

Copyright $(2021$ Gao and Xiong. This is an open-access article distributed under the terms of the Creative Commons Attribution License (CC BY). The use, distribution or reproduction in other forums is permitted, provided the original author $(s)$ and the copyright owner(s) are credited and that the original publication in this journal is cited, in accordance with accepted academic practice. No use, distribution or reproduction is permitted which does not comply with these terms. 